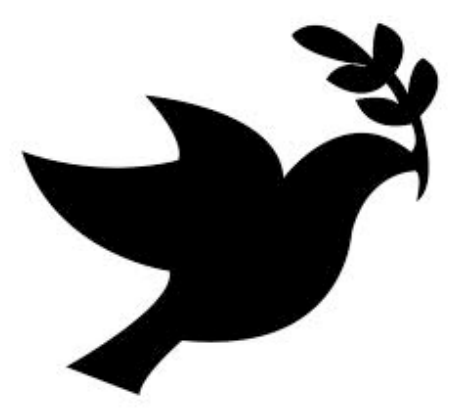

\title{
THE BIGGER PICTURE:
}

An examination of socially conscious art and design produced by Armando Milani and John Quigley in collaboration with the United Nations

Azza Abbaro

Major Research Project - Masters of Professional Communication

Ryerson University, Toronto, Canada

Supervisor: Dr. Joanne Di Nova

Second Reader: Dr. Janice Fung

August 15, 2012 


\section{AUTHORSDEQARATONPACE}

I hereby declare that I am the sole author of this Major Research Paper.

I authorize Ryerson University to lend this MRP to other institutions or individuals for the purpose of scholarly research.

Signature

I further authorize Ryerson University to reproduce this MRP by photocopying or by other means, in total or in part, at the request of other institutions or individuals for the purpose of scholarly research.

Signature 


\section{ABSTRACT}

This thesis explores the ideology of the United Nations (UN) as manifested through external visual communications materials which have been produced in collaboration with artists and graphic designers since the organization's inception in 1945. Initial research showed frequent usage of the symbols of the dove and olive branch, which have been known to connote "peace" over time and across a variety of cultures. A detailed examination of two specific works of socially conscious art and design, Translating War Into Peace and Pablo Picasso's Peace Dove by Palestinian Children in Jericho, shows the multilayered and more meaningful adoption of these symbols by their respective designer Armando Milani and artist John Quigley. Using the theoretical framework of visual social semiotics and the "visual grammar" outlined by Gunther Kress and Theo van Leeuwen in their seminal work Reading Images, this paper examines how Milani and Quigley have produced compositions that represent how the UN views peacenamely, as a process that requires not just ending wars but working to continuously build peaceful infrastructures.

******

As designers, we certainly don't have the power as politicians have, to change the world.

But, I believe that it is our duty to denounce these dramatic problems and induce people to reflection and reaction.

Armando Milani, Graphic Designer 


\section{ACNNOWEDGEMENIS}

I would like to recognize my supervisor Dr. JoAnne DiNova for her guidance, encouragement, and words of wisdom throughout the course of this project. I also wish to thank my second reader Dr. Janice Fung for her support.

A special thank you to Seifeldin Abbaro of the United Nations Development Program as well as Dr. Idris Higazy and Ayeh Naraghi of the United Nations Education Scientific and Cultural Organization and for their help with preliminary research for this paper.

Finally, heartfelt gratitude also goes to my peers and Professors throughout the MPC 2011-2012 program. 


\section{DEDICATION \\ ســـــــاللهالرحمن الرحيـم}

For my family of ever-wandering nomads, who continue to spend their lives supporting a global culture of peace. 


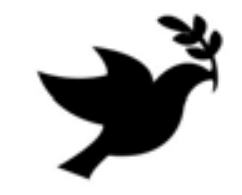

\title{
THE BIGGER PICTURE:
}

An examination of socially conscious art and design produced by Armando Milani and John Quigley in collaboration with the United Nations AzzaAbbaro

\section{TABLE OF CONTENTS}

Author's declaration - 2

\author{
Abstract - 3 \\ Acknowledgements - 4 \\ Dedication - 5 \\ List of figures -7 \\ List of appendices - 7
Main Body
Introduction -8
Images to be Analyzed - 10
Reasons for Study - 11

Theoretical Framework \& Background on Visual Social Semiotics - 13

Background Subsection 1: The Social Construction of Visual Texts - 17

"Background" Subsection 2: Visual Social Semiotics as an Analytical Tool - 20

Literature Review on Visual Social Semiotics - 24

Methodology - 31

Methodology Subsection 1: Clarification of "Socially Conscious Art \& Design" - 36

Methodology Subsection 2: An Exploration of the Symbols in Question - 40

Analysis of Images \& Findings/Interpretations - 45

Final Thoughts - 61

\section{Back Matter}

Appendix 1: First Things First 2000 - 64

Reference List - 66 


\section{UST OF FGRES}

Figure 1: Silhouette of a dove and olive branch

Figure 2: Translating War Into Peace (poster) Armando Milani, 2004

Figure 3: Pablo Picasso's Peace Dove by Palestinian Children at Jericho (Spectral Q Aerial Art project) John Quigley in collaboration with United Nations Relief Works Agency (UNRWA), November 2011

Figure 4: Halliday's Systemic Functional Grammar and Kress \& Van Leeuwen’s Visual Grammar

Figure 5: The United Nations Emblem

Figure 6: A sample of stamps, logos, and images featuring the UN's recurring use of the dove and olive branch symbols in their various external communications materials

Figure 7: A 5-piece gift set from UN Bookshop featuring Armando Milani's Translating War Into Peace, 2004

Figure 8: Peace Dove (drawing) Pablo Picasso, circa 1949

Figure 9: World Peace Congress Poster, Pablo Picasso, 1949

\section{UST OF APPENDICES}

Appendix 1: First Things First 2000 Manifesto 


\section{INIR:ODUCTION}

Visual social semioticians Gunther Kress and Theo Van Leeuwen argue that “...images of whatever kind [are] entirely within the realm of the realizations and instantiations of ideology, as means-always-for the articulation of ideological positions" (2006, p. 14). In other words, imagemakers (artists, designers, film makers, etc.) all make specific choices in the construction of their work so that it may influence its viewers in a pre-determined and particular way. Since its inception in 1945, the United Nations (UN) has noted and taken advantage of this power to influence through images. The organization was founded by fifty-one countries at the end of the Second World War and is according to its mandate "committed to maintaining international peace and security, developing friendly relations among nations and promoting social progress, better living standards and human rights" ("The united nations", 2012, para. 1). For almost seven decades, artists and designers have been partnering with this massive organization to visually promote its values to international audiences through external visual communications materials such as artworks, stamps, posters, postcards, etc. (Sasaki, 2003, para. 12).

In a significant portion of these visual texts, there are two symbols that recur quite frequently, and often together: the dove and olive branch.

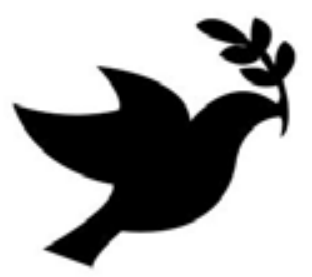

Figure 1: Silhouette of a dove and olive branch

Long understood to mean "peace," the UN has consistently operationalized these symbols in visual materials related to its corporate identity, virtually branding itself with this popular emblem. There are two specific images from the UN's visual corpus, however, that stand out in their multilayered and more meaningful adoption of these peace symbols: Armando Milano's 
Translating War Into Peace poster (fig. 2), and John Quigley's Pablo Picasso's Peace Dove by Palestinian Children at Jericho project in Palestine (fig. 3). Each of these works is created in collaboration with the UN in a very specific medium and, as such, each designer/artist executes their messaging quite uniquely in an effort to get viewers to see a "bigger picture" regarding the UN's ideology.

Using Kress and Van Leeuwen's analytical theory of visual social semiotics, this MRP shall conduct a detailed exploration of these two images in order to ask: What does the external visualcommunication corpus of the United Nations tell us about their ideology? I shall begin by briefly examining the theory and implications of visual social semiotics in the field of visual culture and then outlining my methodology. In this broad field, Milani and Quigley's works can be seen as examples of socially conscious art and design—or images that are intended to visually highlight important social and global issues. I shall then provide the reader with clarification of the concept of "socially conscious art and design" since "semiological studies require extensive knowledge of the type of image [their] case study will examine" (Rose, 2012, p. 109). A brief look at the historical meaning and usage of the dove and olive branch as symbols over time will add further depth to our discussion of their adoption by the UN at large and, specifically, by Quigley and Milani in their unique works. Since these peace symbols have a "pictorial content" that plain text simply does not, examining their history-i.e., how they came to mean peace in the first placecan help us determine "what there is in peace that is shaped by a certain cultural moment" as well as what makes the symbols universally appealing (Rosenthal, 1994, p. 178). Finally, I shall conclude with the analysis of the images and my findings. 


\section{IMAGES TO BE ANALYZED}

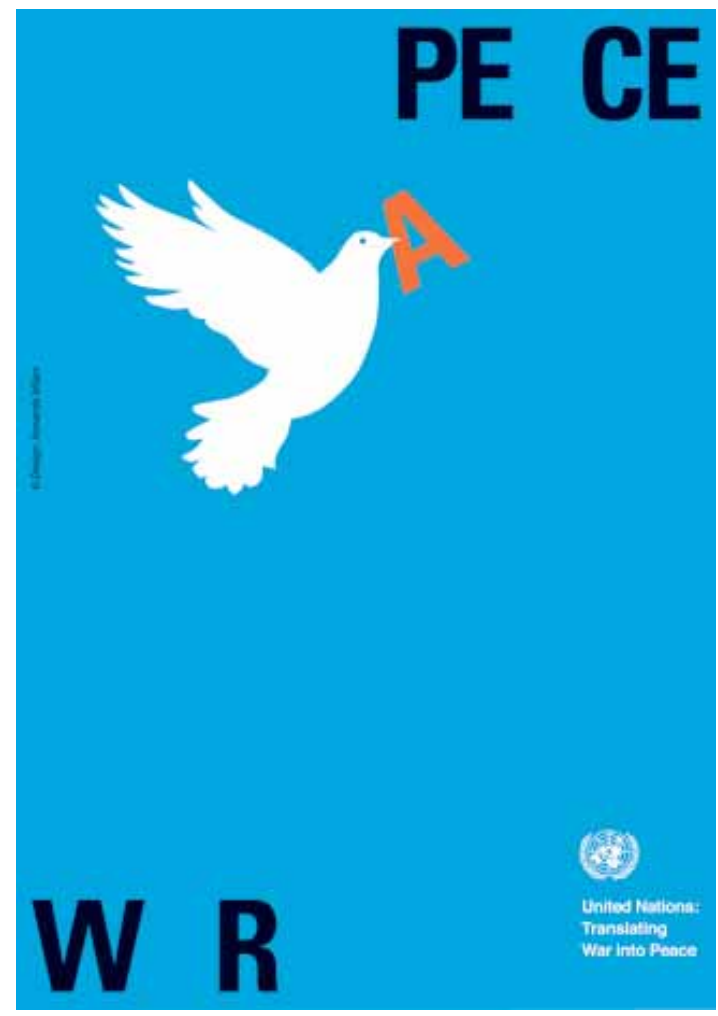

Figure 2: Translating War Into Peace (poster) Armando Milani, 2004

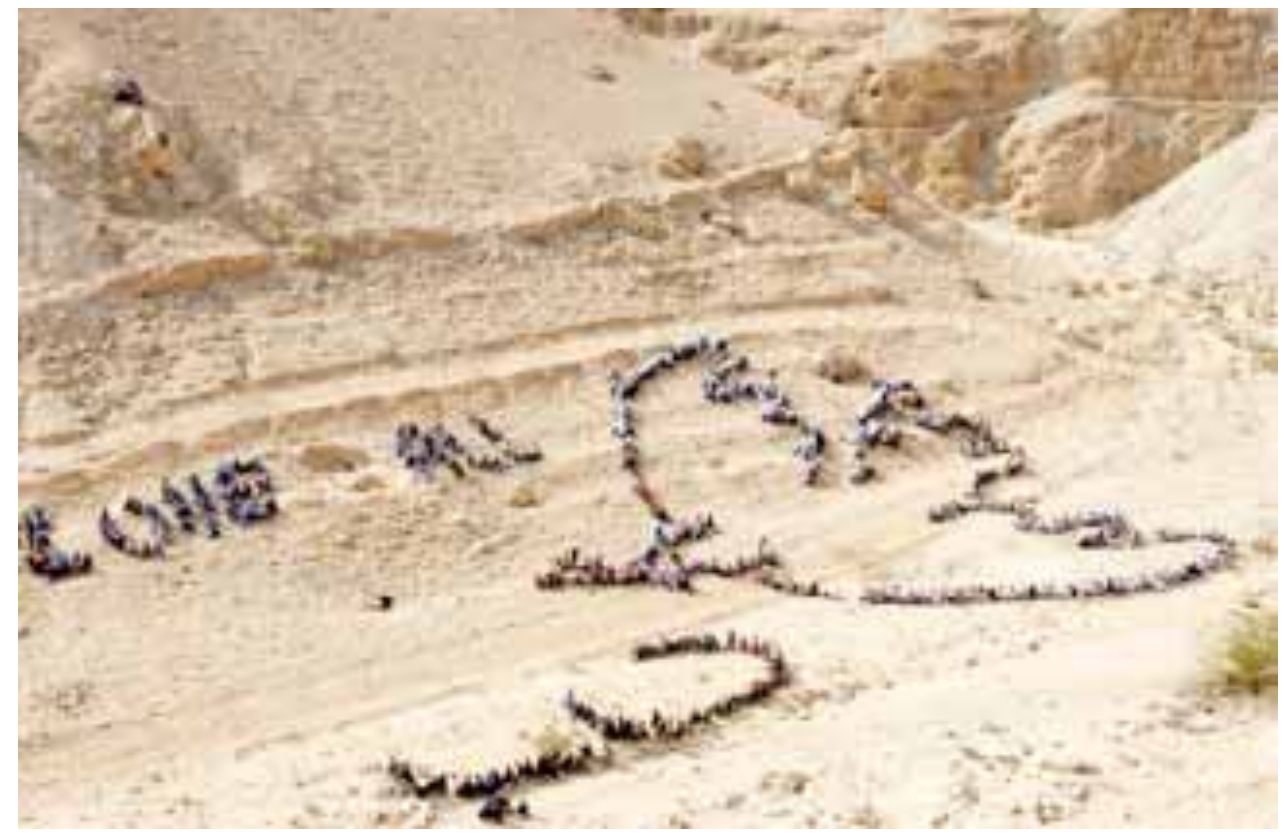

Figure 3: Pablo Picasso's Peace Dove by Palestinian Children at Jericho (Spectral Q Aerial Art project) John Quigley in collaboration with United Nations Relief Works Agency (UNRWA), November 2011 


\section{REASONS FOR STUDY}

In the last few decades, scholars in the field of visual culture have noted a trend towards occularcentricism, with Marita Sturken and Lisa Cartwright claiming that "over the course of the last two centuries, Western culture has come to be dominated by visual rather than oral or textual media... [and that] images have never been merely illustrations, they carry important content" (Sturken \& Cartwright, 2000, p. 1). In modern urban capitalistic societies, this content is comprised largely of advertising, with profit-driven graphics addressing audiences based on their economic status as consumers (Bernard, 1997, para. 30). While historically artists and graphic designers have played a more technical role in the production of such visual messages (layout and composition, type-setting, etc.), an increasing number of skilled visual technicians-like Milani and Quigley_are choosing to apply their talents in other more socially aware contexts, beyond the capitalistic realm of commodity culture. I wish to draw attention to this issue. Today, designers in several fields are developing a more "clearly defined socio-professional profile" as well as a deeper awareness of their role and responsibility in society-not just regarding the look of their designs, but also their content and general purpose in society (Frascara, Kalsi, \& Kneebone, 1987, para. 4). Partnerships between socially conscious artists/designers and social-action-oriented organizations (such as charities, non profits, NGO's, etc.) can prove to be mutually beneficial, with designers having a context in which to apply their skills and the organizations getting their various messages across in a strategic and informed manner. An increase in these types of relationships may also result in a visual culture less driven by profit-minded design and ideologies. Although there is a growing body of literature dedicated specifically to socially conscious art and design, there is a noted research gap with regards to the analysis of such projects using a viable analytical theory. I wish to address this gap by applying Kress and Van Leeuwen's 
theory of visual social semiotics to Milani and Quigley's works in order to determine what semiotic resources these artists/designers have utilized in order to visually manifest the UN's ideology. Knowledge of these resources and a solid theory in which to ground image analysis can help equip designers wishing to engage in this type of work with the skills and critical/analytical mindset necessary to produce "work that is memorable, has a degree of originality, and that merges form and function creates value on many levels" (Bowers, 2008, p.11). Furthermore, at their best, such projects are meant to influence us - their viewers - to reflect on the issues they call to our attention, potentially inspiring us into some form of positive action. 


\section{THEORETICAL FRAMEWORK \& BACKGROUND ON MSUAL SOOAL SEMOICS}

Visual social semiotics is an analytical theory developed in the early nineties by Australian design scholars Gunther Kress and Theo Van Leeuwen. It is grounded in the assumption that all modes of communication— be they verbal, visual, or multimodal—are socially and culturally constructed and that, as a result, images and texts can be deconstructed in a categorical manner in order to reveal meanings and ideologies that are buried in visual semiotic motifs. If semiotics is said to be the study of signs, then visual social semiotics can be considered its visual counterpart. According to Claire Harrison, signs exist as a part of semiotic systems. She gives the example of traffic lights, with each of the three colors in that semiotic system indicating a different action (green is interpreted as "go," yellow as "take caution," and red as "stop"). Words, then, can be considered the signs within the semiotic system of language, and gestures the signs within the semiotic system of nonverbal communication, etc.: "Because semiotic systems encompass the entire range of human practices, Semiotics provides us with a potentially unifying conceptual framework and a set of methods and terms for use across the full range of signifying practices, which include" imagery through photography, film, design, etc. (Harrison, 2003, p. 4748).

The pervasiveness of images in our current climate is cited as one of the main reasons for the development of the theory of visual social semiotics. Kress and Van Leeuwen claim that:

Verbal language is being displaced as a communicational mode by image, in many sites of public communication: whether in school textbooks, in newspapers, in reports produced in institutions of all kinds, in the electronic media, and in the information and communication technologies in general. Image has ceased to be there as mere illustration; that is, as an embellishment of the central, the written text. Image is now fully communicational in very many forms of text. [Italics added for emphasis.] This means that neither linguistics nor sociolinguistics is any longer 
sufficient as the theoretical enterprise to account fully and plausibly for central aspects of representation and communication (2006, p. 67).

As a result, Kress and Van Leeuwen set out to address this scholarly gap. One site of inspiration for their theory was an unpublished report written in the mid 1980's by a Professor of Human Communication at Murdoch University, of Western Australia. Michael O'Toole proposed that Michael Halliday's systemic-functional linguistics offered "a powerful and flexible model for the study of other semiotic codes besides natural language and its universality may be of particular value in evolving new discoveries about art" (p. 1). His proposal was elaborated in the journal Semiotica (O'Toole, 1990) as a systemic functional semiotics of art, and subsequently has been demonstrated to be effective across the range of painting, sculpture and architecture" (Riley, 2004, p.295). Drawing from Halliday's work, Kress and Van Leewuen were able to traverse uncharted semiotic waters and develop a systemic-functional visual counterpart to Halliday's linguistic theory. Their seminal work Reading Images: A Grammar of Visual Design was published in 1996 and outlined this new approach to image analysis. In creating a visual grammar (VG), Kress and Van Leeuwen were able to demonstrate how the "visual semiotic mode...can function as an autonomous communicational system in providing a full descriptive framework for the analysis of through the grammar" outlined and described in their book (Almeida 494). For the purposes of this study, I will be using the second and most recent edition of Reading Images, published in 2006.

In their textbook, Kress and Van Leeuwen demonstrate their framework by analyzing pictures from a wide variety of sources, mixing paintings, diagrams, film frames, school book illustrations, newspaper photographs, technical drawings, emblems, etc. Charles Forceville tells us that their strategy is refreshing and potentially innovative: "If the authors succeed in demonstrating the general applicability of a certain concept, irrespective of the type of picture, 
they genuinely help advance the theory of pictorial representation" (1999, p.172).

The following figure demonstrates the analogical parallels between Halliday's Systemic Functional Grammar (SFG) and Kress and Van Leeuwen's Grammar of Visual Design (VG):

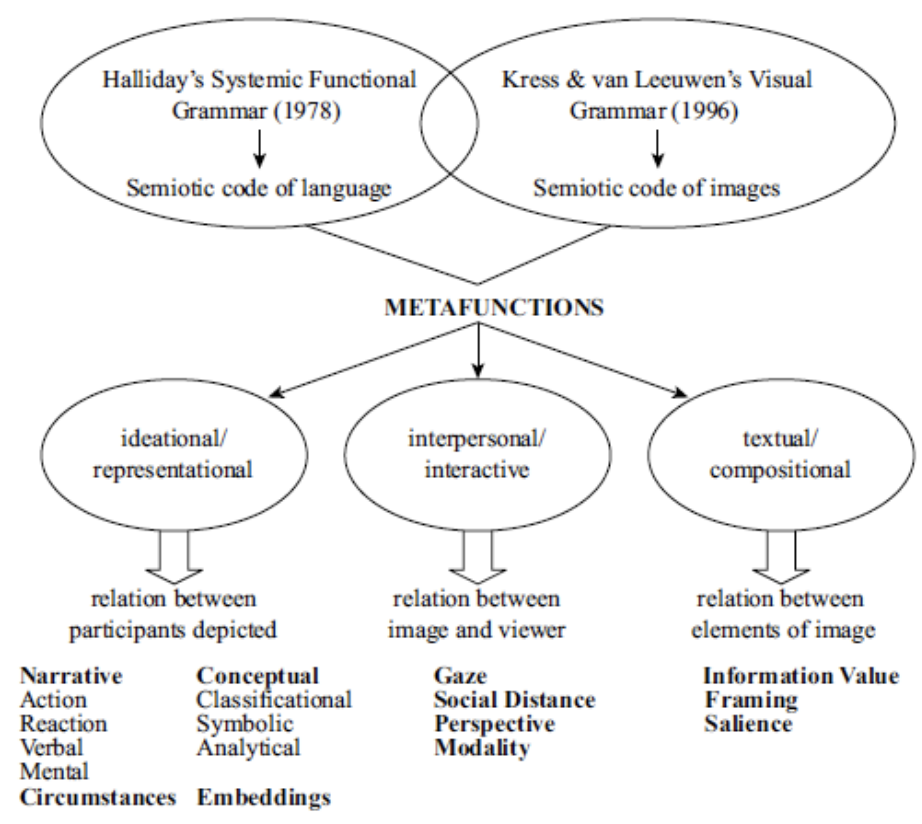

Figure 4: Halliday's Systemic Functional Grammar and Kress \& Van Leeuwen's Visual Grammar.

Similar to Halliday's framework, visual social semiotics assumes that images "can be described in terms of the three types of functions that operate simultaneously via the patterns of experience, social interaction and ideological positions that both linguistic and non-linguistic types of representation encode, namely, metafunctions" (Almeida, 2009 p.484). These three metafunctions are the ideational metafunction (also called representational), the interpersonal metafunction (also called interactive), and the textual metafunction (also called compositional) (Jewitt and Oyama, Almeida, 2009, p. 484). For the purposes of this study, I shall use the terms outlined by Kress and Van Leeuwen's in their second edition of the textbook Reading Images: ideational, interpersonal, and textual. I shall elaborate on these metafunctions in the Methodology section of the MRP, as 
they are key to our analysis of Milani and Quigley's images. For now, however, it is important to understand Kress and Van Leeuwen's essential argument, which is that their framework and grammar can be used to analyze images, and that this analysis will reveal the semiotic choices made at the time the image was being produced. As such, their theory is concerned with analyzing the site of sign-making, where "the signifier (the form) and the signified (the meaning) are relatively independent of each other until they are brought together by the sign-maker in a newly made sign" (Kress \& Van Leeuwen, 2006, p. 8). The "signs" of which they speak are present in all forms of visual communication, whether they appear in the public domain (via public notices, the press, advertising, sites of public transport) or in 'in somewhat more 'private' domains, in the home, and in markets and shops, for instance" (Kress \& Van Leeuwen, 2006, p. 4). Wherever visual communication occurs, there is a potential for analysis using Kress and Van Leeuwen's framework. However the theorists are quick to point out that their visual grammar is not at all universal, and that it has its semiotic roots specifically in Western visual communication; as such it can only account for images in Western society. Furthermore they acknowledge that even within this taxonomy there maybe some regional and social variation (Forceville, 1999, p.164). Indeed, the majority of the images used as examples to reveal visual semiotic structures in Reading Images are derived from Western locales (Australian school textbooks, American print ads, personal photographs taken in Europe, etc.). Despite this, however, the authors cite the international prevalence of Western imagery, claiming that "in many parts of the world, Western visual communication exists side by side with local forms," implying a usefulness for their theory beyond a Western context. Nevertheless the authors purport that even "though others have begun to extend the applications of the principles of [our] grammar, we make no specific claims for the application of our ideas to other cultures. Within Western visual design, however, we believe that 
our theory applies to all forms of visual communication" (Kress and Van Leeuwen, 2006, p. 4). Milani and Quigley's images are examples of Western visual design, clearly indicated by the use of English text in both images. As a result, an analysis using Kress and Van Leeuwen's grammar will reveal the semiotic choices made during the creation of these works and what these choices mean for the audience viewing these images. Deriving this meaning will give us insight into the ideology of the United Nations.

\section{BAOKGOND The Sodial Constrution of Visual Texts}

Because visual social semiotics was largely inspired by critical linguistics, the theory also borrows much of its analytical techniques and terminology from the founders of traditional semiotics, Charles S. Peirce and Ferdinand de Saussure, who were apparently "neither interested in visual analysis or ideology." However their philosophical models were vital to laying the theoretical groundwork of cultural theory, and eventually visual social semiotics (Aiello, 2006, p.92). According to Giorgia Aiello, this analytical approach is formal and entails a shift of focus onto the text itself. However, unlike traditional semiotics, "social semiotics does not see ideology as one of the components or layers of signification, but rather as its premise. Iedema (2001) emphasizes that social semioticians believe that texts are never made by accident. Like cultural studies, social semiotics assumes that "the power to signify is not a neutral force" (Hall, 1982, p. 70). As previously mentioned, a fundamental belief of social semioticians is that all modes of communication —whether verbal, textual, or multimodal—are socially and culturally constructed. Much like authors consider word choice and order when developing prose, artists and designers (whom Kress and Van Leeuwen call sign-makers) must consider what compositional elements to use to communicate their visual message. The theorists state that "language and visual communication both realize the same more fundamental and far-reaching systems of meaning that 
constitute our cultures, but that each does so by means of its own specific forms, and independently [and that] not everything that can be realized in language can also be realized by means of images, or vice versa" (Kress \& Van Leeuwen, 1996, p. 17). Like linguistic structures, Kress and Van Leeuwen argue that visual grammar also goes beyond the "formal rules of correctness to represent patterns of experience" which point to particular interpretations of experience and forms of social interaction: "It enables human beings to build a mental picture of reality, to make sense of their experience of what goes on around them and inside them... [As a result,] meanings belong to culture, rather than to specific semiotic modes. And the way meanings are mapped across different semiotic modes...is also culturally and historically specific" (Kress \& Van Leeuwen, 2006, p.2). As an example, they cite how the same story can be presented in two different ways in newspapers, depending on political viewpoints. Kress and Van Leeuwen also purport that there is no fundamental difference between creative, artistic uses of pictures and communicative ordinary uses-rather it is a continuum: "But for each type of image they argue that the inclusion or exclusion of details, and the manner of execution, can have ideological implications, and emphasize their concern with this aspect of pictures, seeing their work as 'a tool for practical as well as critical applications in a range of fields' (p. 14)" (Forceville, 1999, p.164). Claire Harrison argues that as a critical methodology, visual social semiotics is unique in that although it is not the sole theoretical framework for examining how images convey meaning, "others include Gestalt theory, art history, psychoanalytical image analysis, and iconography, to name a few, it [stresses] that an image is not the result of a singular, isolated, creative activity, but is itself a social process. As such, its meaning is a negotiation between the producer and the viewer, reflecting their individual social/cultural/ political beliefs, values, and attitudes" (Harrison, 2003, p.47). 
According to Gillian Rose (2012) semiology is influential in its approach to analyzing and interpreting the materials of visual culture because it draws from the work of a number of theorists who have had considerable impact on the social sciences since the 1960's. She mentions Judith Williamson's (1978) classic semiological study, Decoding Advertisments, as citing Althusser, Barthes, Benjamin, Berger, Brecht, Foucault, Freud, Gramsci, Lacan, Levi-Strauss, Marx and Saussure, "a roll-call of many of the twentieth century's most important critical writers" (Rose, 2012, p.105-106). Aiello claims that de Saussure's follower Roland Barthes was one of the first semiologists to look at "signs and signification as dynamic elements of any given social and cultural fabric. Whereas de Saussure had looked at signification in culture in a synchronic manner (as if frozen in time), Barthes was interested in how meanings change across cultural and historical contexts... under his influence the term semiology has become more broadly associated with an interest in the analysis of cultural practices and, specifically, popular culture. (Barthes was particularly interested in the role of photography in mass communication)" (Aiello, 2006, p.94). From a technical standpoint then, visual social semiotics is interested in the formal deconstruction of compositional elements within an image. Yet from a critical standpoint, it is about revealing the power structures that have supposedly been embedded in images through strategic compositional semiotic choices: "Not unlike cultural studies, social semiotics sees signification as social practice, that is, as a process deeply embedded in and affected by existing cultural norms and power structures. However, social semiotics' emphasis is on the specific semiotic resources that are mobilized in a given text. Its focus is primarily on the ways in which given visual strategies can be deployed within and across texts to achieve ideological ends" (Aiello, 2006, p. 98). However, one notable difference between Kress and Van Leeuwen's theory and that of traditional European semiology is that while de Saussure is assumed to have said that the relationship 
between signifier and that which is signified is arbitrary, Kress and Van Leeuwen argue that this relationship is...

...always motivated and conventional. Where [de Saussure] had seemingly placed semiotic weight and power with the social, we wish to assert the effects of the transformative role of individual agents, yet also the constant presence of the social: in the historical shaping of the resources, in the individual agent's social history, in the recognition of present conventions, in the effect of the environment in which representation and communication happen. Yet it is the transformative action of individuals, along the contours of social givens, which constantly reshapes the resources, and makes possible the self-making of social subjects. (Kress \& Van Leeuwen, 2006, p.12)

This shift of attention from the sign to the social is crucial to understanding this theory. Though partially analytic in nature, Rose claims that visual social semiologists "defend on a definition of science that contrasts scientific knowledge with ideology (this distinction is usually elaborated with reference to the Marxist theorist Louis Althusser). Ideology is knowledge that is constructed in such a way as to legitimate unequal social power relations; science, instead, is knowledge that reveals those inequalities. This use of the term ideology is evident of the formative influence of Marxism on semiology" (Rose, 2012, p.106).

\section{BACKGROUND: Visual Social Semiotics as an Analytical Tool}

In the context of professional communication then, what are being analyzed are the semiotic choices being made by sign-makers (designers, artists, and other image makers) at the site of production. It is here where the social and cultural constructions-which are reflected in the images being produced and disseminated—that Kress and Van Leeuwen refer to materialize. As such, designers and artists play an undeniable role in the cultural production of meanings through imagery. In describing the ideology of the United Nations, however, I shall be using a less 
pejorative and more neutral definition of ideology as outlined by visual culture researchers Marita Sturken and Lisa Cartwright in their 2001 textbook Practices of Looking. According to Sturken and Cartwright:

To explore the meaning of images is to recognize that they are produced within dynamics of social power and ideology. Ideologies are systems of belief that exist within all cultures. Images are important means through which ideologies are produced and onto which ideologies are projected. When people think of ideologies, they often think in terms of propaganda - the crude process of using false representations to lure people into holding beliefs that may compromise their own interest. This understanding ideology assumes that to act ideologically is to act out of ignorance. In this particular sense, the term "ideology" carries a pejorative cast. However, ideology is a much more pervasive, mundane process in which we all engage, whether we are aware of it or not. For our purposes, we define ideology as the broad but indispensable, shared set of values and beliefs through which individuals live out their complex relations to a range of social structures (2001, p.21).

While we shall revisit this idea a bit further in the MRP, I now wish to address the implications of Kress and Van Leeuwen's theory.

Though admittedly Eurocentric in nature, Kress and Van Leeuwen's theory provides an effective tool "for understanding many conventions found in Western imagery that, despite people's differences in age, ethnicity, gender, and so on, evoke generally uniform reactions" (Harrison, 2003, p.58). Knowledge of visual social semiotics can be especially useful to professional visual communicators (and scholars) in helping them better understand how compositional and semiotic choices are used in visual rhetoric in several contexts. For example, the various analyses that have been conducted on advertisements-including by Kress and Van Leeuwen themselves-reveal underlying strategies used to persuade consumers into participating in commodity culture. As such, knowledge of visual social semiotics can also help increase 
general visual literacy, since awareness of the conventions of visual messaging can help us better understand our visual landscape as well as the semiotic strategies used in the visual communication materials we come across every day. Kress and Van Leeuwen argue that this is imperative in an increasingly visually oriented, or occularcentric, world. In fact, both scholars believe that visual communication is becoming less and less of a specialist's domain, as it is more and more crucial to the arena of public communication. This, both argue, will lead to new and more rules, as well as to more "formal, normative teaching. Not being 'visually literate' will begin to attract social sanctions. 'Visual literacy' will begin to be a matter of survival, especially in the workplace" (Kress \& Van Leeuwen, 2006, p.3). Claire Harrison is careful to point out, however, that despite knowledge of visual grammar and conventions, there are different design solutions to different design problems, and that visual social semiotics "may not be able to answer all the issues that an image may raise" (Harrison, 2003, p. 49). For example, ten different designers who are given the same task might produce ten completely different images with varying effects through their choices in style and aesthetics. While visual social semiotics does not necessarily address these two concepts in its framework (like why a certain design might be prone to a specific style or aesthetic), she argues that it is nevertheless "an extremely useful tool for analyzing images and their relationship to text" (Harrison, 2003, p.49).

There are also a handful of concerns that scholars have brought up with regards to visual social semiotics. One issue is that the socially constructed sign system that it is so dependent on is naturally subject to change: "This raises the question: what determines any particular way of seeing? What we notice...[is] conditioned by the kinds of language-determined realities that form us as social beings. Those socially constructed realities, and language itself, are subject to transformation through innovations in [both] the ways we see" and make imagery (Riley 2004, p. 
296). Furthermore, Forceville (1999) warns that while in language grammaticality is somewhat stable across text-genres, when it comes to images it is much more genre-dependent—in other words the meanings derived from the images will depend on its particular medium (p.172). Another criticism of visual social semiotics—and indeed of semiology in all its forms-is the theory's tendency to continuously invent new terminology as it expands. While the terms are often useful, built on previous delineations, and are clearly defined, they are prone to cause confusion if one is not well aware of their multiplicity (Rose, 2012, p.145). Perfect examples are the abovementioned varying terms used for an image's three metafunctions. Despite these concerns, however, Kress and Van Leeuwen are generally commended for "pioneering largely unexplored territory," and critiques of their theory are only intended to improve its scholarly applications. To date, the theory continues to be used and expanded, not just in the realm of stillprint images, but in all sorts of multi-media documents and technological contexts. 


\section{ITIRATURE REMEWON USUALSOOALSGMOTIS}

Being a relatively young theory, the literature on visual social semiotics is somewhat limited and takes the form of image case studies-much like this MRP shall be. Theoretically, visual social semiotics "considers all visual texts as having been developed to perform specific actions, or semiotic work" (Aiello, 2006, p.91). Methodologically, it functions as an analytical tool and is most frequently applied by researchers to visual texts in order to reveal semiotic choices, motifs, and patterns which enables them to make broader statements or arguments about the context in which these visual texts are created: "The structuralist semiotic approach to representation has been typically interested in deconstructing texts in order to identify codes, or sets of rules that are agreed upon within a given cultural system, and that thus allow the members of the same culture to understand each other by attaching the same meanings to the same signs" (Aiello, 2006, p.91). One of the reasons for this systematic deconstruction of images is subjecting them to a thorough critical analysis to help decipher who made the rules [in the context being studied] and how and why they might be changed" (Jewitt \& Oyama, 2001, p. 135). This attention to the "social" is one of the key issues of visual social semioticians, and it is perhaps for this reason that the theory has been applied rather frequently to advertisements. According to Gillian Rose, much of the literature in mainstream semiology is situated in corporate imagery and analyzes advertisements "because they are core to the ideologies structuring contemporary society" (Rose, 2012, p.109). Furthermore, corporate imagery is ripe for critical analysis by communication scholars because "it is so explicitly designed to generate economic capital through the exploitation and creation of symbolic capital"-and indeed wherever there is exploitation, there are ideologies to uncover (Aiello \& Thurlow, 2007, p.310). 
In 2007, Giorgia Aiello and Crispin Thurlow conducted a social semiotic analysis on one particular semiotic site: airline tailfin designs, a context that they argue is a ubiquitous, everyday visual genre. By examining the compositions of 561 tailfins, Aiello \& Thurlow were interested in gaining insight regarding global visual communication practices. Their main intention was to use this kind of micro-level analysis to reveal the discourses "which frame and inscribe the genre and, in turn $[\ldots]$ showing how the genre reframes and reinscribes these same discourses" (Thurlow \& Aiello, 2007, p.307). By doing this, they were subsequently able to demonstrate the ways in which textual practices or communicative events that seem innocent actually "reconstitute important areas of social life and...reconfigure the meaning of cultural spaces" (Thurlow \& Aiello, 2007, p.307). Through their study, Thurlow and Aiello were able to expose how notions of nationalism got translated into corporate visual identities through specific semiotic design elements. Their findings highlight the notion that tailfin designs often draw from national emblems and stereotypes, which are then "exploited by marketers (and others, e.g. politicians) for economic and political gain. Thurlow and Jaworski (2003) refer to this as the 'globalization of nationality" (Thurlow \& Aiello, 2007, p.332). Such specialized analyses can demonstrate how concepts such as capitalism and globalism (in this case, both) actually play out in the real world: "however insignificant or innocent these semiotic moments may seem, they act as channels and agents of global capital" (Aiello \& Thurlow, 2007, p.337). Aiello and Thurlow cite Normal Fairclough's concept of 'textualization,' 'the process whereby social and economic realities are represented and established discursively"-in this case through the brand imagery of tailfins (Thurlow \& Aiello, 2007, p.337). As such, an analyses of these practices sheds light on how strategic design practices are affected by a multitude of factors, especially when it comes to issues of national visual identity within a global economy. 
More recently, Danielle Almeida examined which social contexts get represented in advertisements for fashion dolls and what subsequent relationships become established between the "participants" involved (i.e. the viewers of the ads). Almeida argues that in the age of consumerism, toys have become like icons, and that through "features such as design, advertising images and marketing-language-produced texts, toys convey messages that reflect the cultural and social meanings of the world surrounding them" (Almeida, 481). Through a visual social semiotic reading using Kress and Van Leeuwen's visual grammar and metafunctional framework, Almedia was able to reveal some of the structures of signification behind the visual discourse of these ads (which she retrieved from the website www.mgae.com). One of her most interesting discussions highlighted on how multiculturalism was represented in Bratz dolls:

The multi-ethnicity of the Bratz is marked by their rather distinct aesthetic features such as the color of their skin and their hair type and style, which turn them into semiotic representations of a broad range of racial classes. Yet this ethnic diversity gets diluted by their standardized bodily features: big heads and large eyes, protuberant lips and unrealistic feet that can be popped off. Be that as it may, the portrayal of such multiculturalism through a semiotic representation such as the Bratz dolls conveys the social and cultural hybridism that is deeply rooted in the historic formation of US society (Almeida, 2009, p.483).

Through her analysis, Almedia was able to suggest that "contemporary advertised representations of women such as the US dolls under investigation, strongly emphasize women's physical appearance, and their heavy reliance on fashion trends and beauty necessities relegates them to a position of subservience in relation to the industry of consumerism" (Almedia, 2009, p.499). This strong statement is somewhat typical of studies that use visual social semiotics to reveal the "hidden" power structures in advertisements and how they are represented through conscious semiotic choices. Aiello and Thurlow claim that corporate branders/designers, despite being 
"unquestionably very astute and skilled at what they do; seldom... have an articulate (meta)language for explaining how it is that their designs 'work'. Nor are commercial agents often inclined to reflect on the ways their practices function ideologically and politically" (Aiello \& Thurlow, 2007, p.337). As such, it is crucial for studies like Aiello, Thurlow, and Almedia's to take place-not just to fill the scholarly gap with a functional and articulate design "metalanguage," but to increase visual literacy in general. Through systematic visual analyses using Kress and VanLeewuen's grammar, images (whether advertisements or airline tailfins) become somewhat demystified — they are no longer seen as "neutral vehicles of entertainment and replicas of reality." Visual social semiotics gives us a useful tool to help us analyze visually communicative modes that are filled with cultural and political biases-in short, it gives us a grounded perspective rooted in social critique (Almeida, 2009, p.484).

As previously mentioned, however, not all studies using visual social semiotics are of advertisements, or indeed of still images. In 2001, Rick Iedema analyzed a documentary that is set in a Melbourne hospital and examines budget-management-related conflicts between doctors and administrators. Using the three metafunctions, Iedema was able to discern that the documentary favored the doctors. His analysis showed that the doctors were represented as more active and were filmed at certain camera angles which allows viewers of the film to see them as less socially distant than the administrators, who were filmed from a low angle (Aiello, 2006, p. 92). Iedema's findings relate to Kress and VanLeewen's concepts of representation and interaction or orientation respectively, in which film or photographical depictions from certain technical perspectives (for example high versus low angles, a direct view versus a side view, etc. ) allows viewers to interpret the information being presented in specific ways. By applying Kress and Van Leeuwen's framework to the visual mode of films, scholars are able to expand their analyses and discussions 
of power relations as represented through such visual semiotic choices. Gillian Rose also cites a study by Carey Jewitt conducted in 2005 which addressed the "multimodality of multimedia resources designed to teach English and science to secondary students" (Rose, 2012, p.140). Jewitt examines a CD-ROM version of a novel as well as an interactive science CD and investigates how their text and their still and animated visuals are "designed to convey specific meanings: about the characters in the novel, for example, or about the relationships between solids, liquids, and gasses" (Rose, 2012, p.140). What is interesting here is the educational context of Jewitt's study, as it reflects the various means through which information can be and is presented to students - a setting ripe for ideological constructions. According to her biography, Alemida herself conducts projects that focus "not only on the multimodal analysis of media texts but also on pedagogical practices associated with the use of images in the foreign language classroom" (Almeida, 2009, p.92). This once again brings up the issue of visual literacy, but puts it in an institutionalized context.

Not all of the literature on visual social semiotics delves straight into application of Kress and Van Leeuwen's theory, and as we have seen in the previous section, scholars like Forceville have begun looking into how visual social semiotics can be strengthened as a functional theory. Howard Riley argues that the "influence of Australian-based research upon the practice of the visual arts is rather less well known" (Riley, 2004, p.295). Riley’s 2004 study offers supporting evidence that there is "recognition of the need to elaborate and apply a social semiotics of the visual" in the domain of drawing practice, and that this need is being actively addressed (Riley, 2004, p.295). Any and all designs, according to Riley, begin with an "inception stage," where social concepts become encoded into material form. This process usually takes place through drawing, which Riley argues as a visual aesthetic sensibility can be culturally determined: 
Such sensibility is the product of correlations between semiotic codes and the social structures in which those codes have become conventionalized. Visual semiotic codes, those systems of signs we invent to represent and express our attitudes towards aspects of the world, are conditioned by our perceptual experiences of the world. They are the means through which we express the perceptual relations which exist between us as bodies, and our physical environment. Therefore it becomes feasible to suggest a triadic structure linking perceptual modes, ways of drawing and types of social structures (Riley, 2004, p.295).

His study then goes on to propose this model, drawing on the work of Kress and Van Leeuwen and their social semiotic predecessors, as discussed in the "Theoretical Framework..." section of this MRP.

The underlying commonality between scholars who have applied Kress and Van Leeuwen's theory to their research and those who have based their research on expanding the notions of the theory itself is that they concern themselves with broader issues in society as represented through visual means. Although the contexts vary, much of the research is highly influenced by the field of cultural studies in its view of ideology. Cultural studies, which as we have seen is one of the major influences of visual social semiotics "focuses on revealing how dominant cultural norms become embedded in media messages in ways that allow them to be reinforced, internalized, and ultimately also become hegemonic” (Aiello, 2006, p.98). In fact Sturken and Cartwright also claim that we live in an image culture that is a diverse arena of oftenconflicting ideologies:

Images are elements of contemporary advertising and consumer culture through which assumptions about beauty, desire, glamour, and social value are both constructed and responded to. Film and television are media through which we see reinforced ideological constructions such as the value of romantic love, the norm of heterosexuality, nationalism, or traditional concepts of good and evil. The most important aspect of ideologies is that they appear to be natural or given, rather than 
part of a system of belief that a culture produces in order to function in a particular way (Sturken \& Cartwright, 2001, p.21).

While much of the research using Kress and Van Leeuwen's theory has focused on capitalistic and educational contexts, this MRP will be examining images of socially conscious art and design (which I shall elaborate on further along in the paper). Although there is no standardized definition for this type of work, it is largely seen by its practitioners as visual messaging that extends beyond the realm of commodity culture and gets its viewers to think about the state of their environment and perhaps the world at large. In 2008, Sali Sasaki, a freelance designer and former employee of UNESCO, contributed a paper entitled "The Role of Graphic Design in International Development" to the 2008 Design Olympiad in Seoul, Korea. In it, she highlighted the notion that (artists and) graphic designers have become increasingly sensitive to world issues, and that the professional design world is currently encouraging and promoting new social design practices through (for example) collaboration with social-issue oriented organizations. According to Sasaki, the UN has been working with graphic designers to promote their values via posters, book covers, or corporate identity materials for well over 60 years. Despite these collaborations between artists, graphic designers and UN agencies being "relatively inconsistent in the eighties and nineties, graphic design started contributing very positively towards UN goals since the start of the millennium" (Sasaki, 2008, para. 13). In this MRP, I will be examining the ideology of an organization as displayed through its visual materials, using the aforementioned less pejorative definition of ideology outlined by Sturken and Cartwright. It is my belief that these types of images warrant examination because of their positive contributions to the arena of art and design, as well as the attention they bring to social issues in societies bombarded by advertisements and for-profit messaging. 


\section{METHODOLOG}

In my research of the United Nations' visual corpus, I have noted frequent usage of the dove and olive branch symbols in external visual communications materials. This corpus includes a variety of images including logos, stamps, postcards, posters, and other visual texts intended to reach international audiences. The UN and its various bodies have been using these symbols — which are widely understood to connote peace—since its founding well over sixty years ago. This includes the organization's own logo seen here:

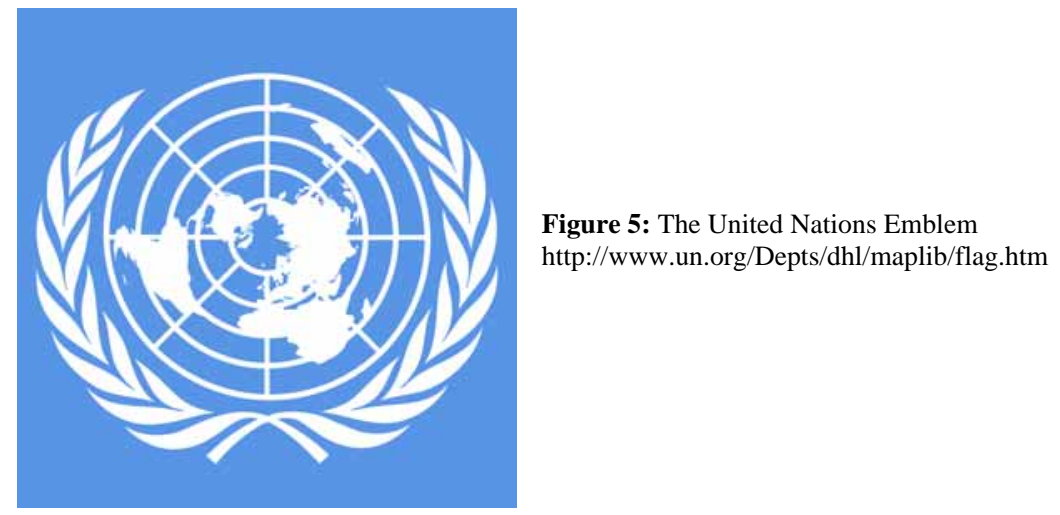

Donald McLaughlin, a graduate of Yale in architecture, designed the emblem in 1945 (Sasaki, 2003, para. 10) and according to the official UN website, it was approved on 7 December 1946. "The design is a map of the world representing an azimuthal equidistant projection centered on the North Pole, inscribed in a wreath consisting of crossed conventionalized branches of the olive tree... Olive branches symbolize peace. The world map depicts the area of concern to the United Nations in achieving its main purpose, peace and security" ("UN Flag and Emblem", 2012, para. 2). Symbolist Peggy Rosenthal claims that the twin olive branches around a world map were "chosen for the UN insignia because of their universal readability as symbols" (Rosenthal, 1994, p. 176). Figure 6 provides a glimpse of how frequently the dove and olive branch symbols feature in the UN's visual corpus: 

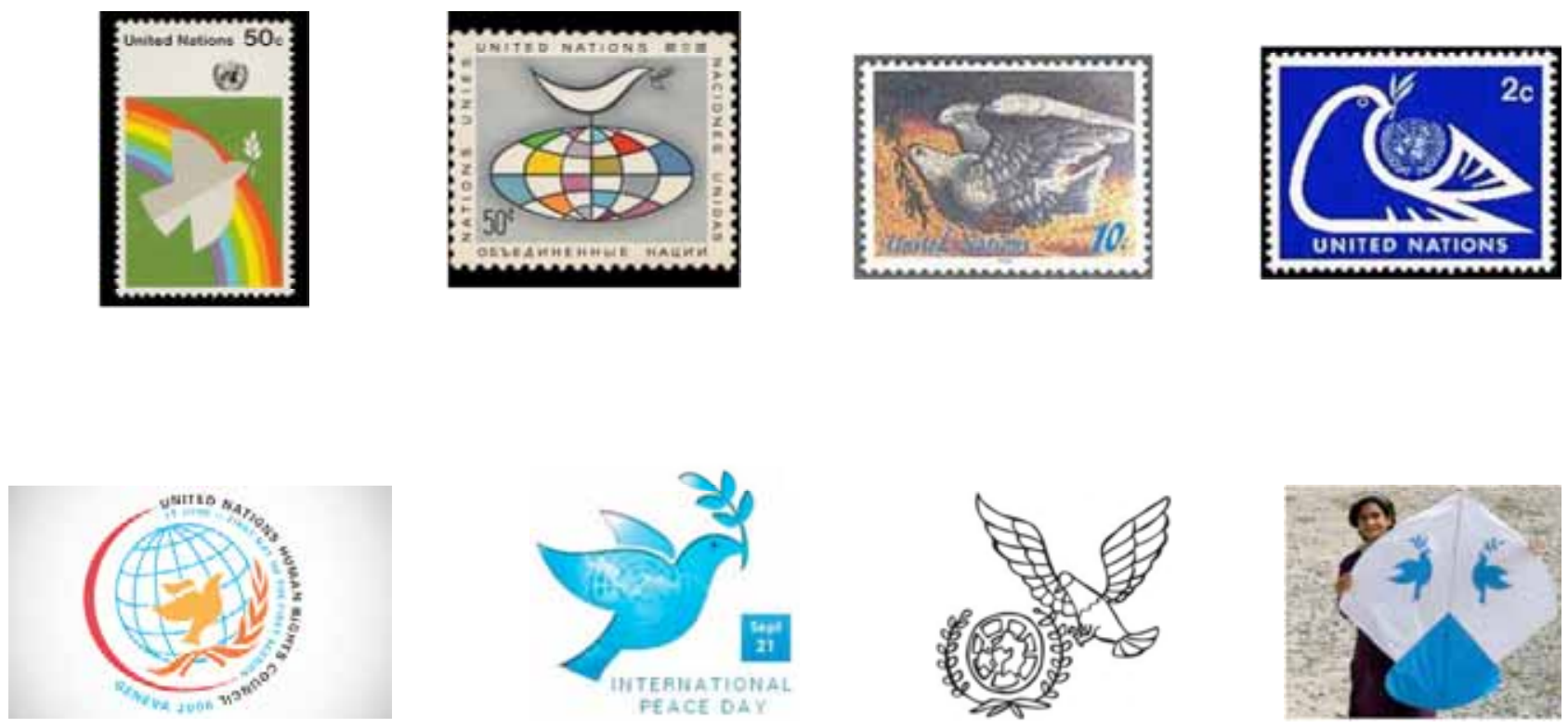

Figure 6: A sample of stamps, logos, and images featuring the UN's recurring use of the dove and olive branch symbols in their various external communications materials

Their usage on stamps is clever and plays on the concept of the dove as a messenger of peace, since airmail implies communication between a sender and receiver. We can also see this symbolic association between "birds" and "messenger" carried forward in the digital world, with the mascot for the microblogging site Twitter as a case in point. Using the symbol on kites that can be flown high for all to see is also apt. However in the majority of these materials, the symbols are more emblematic, helping to brand the UN's visual identity rather than saying something greater about the concept of peace.

Nevertheless there are two particular cultural materials from this visual corpus that adopt the symbols in a more multilayered and meaningful way. As images produced between socially conscious artist/designers and a humanitarian organization, they lend themselves extremely well to a social semiotic analysis, giving us greater insight into the UN's ideology as 
expressed through their visual communications materials: The first of these two works which I will examine is the 2004 Translating War Into Peace poster by Armando Milani (Figure 2). This poster was published and distributed internationally by the United Nations and is one of the organization's most celebrated images. Milani himself claims: “Of all my works this poster has received the most recognition around the world. The UN decided to use it for the celebration of their 60th anniversary. It was also turned into t-shirts, tote bags, watches, magnets, pins and umbrellas" (Milani, 2011, para. 1). The poster's wit and striking simplicity has made it adaptable into several forms of merchandise, which are being disseminated some eight years after it was first designed. This has allowed the UN to widely circulate this image, further promoting their organizational mandate.

The second image I will examine is entitled 'Pablo Picasso's Peace Dove by Palestinian Children at Jericho" (Figure 3). This work was completed by artist John Quigley in cooperation with United Nations Relief and Works Agency (UNWRA). Although the image is similar to Milani in its use of text alongside the symbols of the dove and olive branch, Quigley's messaging technique is altogether different. In November of 2011, the artist rallied just over a thousand Palestinian school children to stand in the formation of Picasso's dove with the words "Love all" written along side it in English and Arabic. This message of peace from one of the world's longest standing conflicts is presented in several aerial photographs of the project such as the one seen in this MRP. What is unique about Quigley's work is his subversion of the idea of simply using pictorial symbols to stand for peace; instead, he uses human subjects as one of the main focal points in the composition of his visual message. He calls this process SpectralQ Aerial Art, with his website claiming that it is "a unique medium of communication that is designed to build community and inspire creativity" (Quigley, 2012, para. 1). This type of work, which 
operates in an arts-based peacebuilding setting, will be described further along in the MRP when we come to analyze Quigley's image.

Milani and Quigley's visual texts were selected from the UN's visual corpus as prime examples of socially conscious art and design produced by United Nations (through its various bodies) in collaboration with international artists. Because they utilize English as the main language of communication (despite Quigley also using Arabic), these two texts can be considered examples of Western imagery, meaning Kress and Van Leeuwen's Eurocentric theory of visual social semiotics can be applied without apprehension. What allows these two works to stand out from other UN visual materials is Milani and Quigley's unique visual techniques (which is essentially what we will be analyzing), as well as their multidimensional usage of the symbols of the dove and olive branch. For both of these works, I will conduct a visual social semiotic reading as well as ask: What do the symbols of the dove and olive branch represent, and how are they being used in the specific context of each design/artwork? What is the message of the design/artwork in relation to the UN? Both Milani and Quigley's images use symbolism to initially draw our attention, since we can immediately identify these symbols and what they connote: peace. However, this is clearly not where their messaging stops. Since both of these works are multimodal (i.e. both utilize images and text), we can argue that the pictorial peace symbols are actually used as only part of a larger rhetorical strategy/narrative. A full reading of the compositional elements of these two images reveals cues that lead our eyes away from the symbol to help us get the artists' "bigger picture." This "bigger picture" is what I am interested in, as it will help answer our main research question: What does the UN's visual corpus tell us about their ideology?

Many semiological studies tend to concentrate on the image itself as the most important site of its meaning. According to Van Leeuwen: "In social semiotics the focus [has] changed from 
the 'sign' to the way people use semiotic 'resources'...to produce communicative artifacts...in the context of specific social situations and practices" (Van Leeuwen, 2005, p.xi). In my effort to decipher these "semiotic resources," I will first explore the history of the symbols in question, since understanding how the dove and olive branch came to signify peace in the first place gives us greater insight into how they have been used in Milani and Quigley's images and, indeed, by the United Nations at large. I will then specifically analyze the three metafunctions within their images. As we have previously seen in the Theoretical Outline section, visual social semiotics borrows heavily from Halliday's functional linguistic framework in its adoption of the three “metafunctions." Kress and Van Leeuwen's essential argument is that an image can be described using these three metafunctions-ideational, textual, and interpersonal—which operate simultaneously and encode several types of representation. Consequently, an analysis using their visual grammar will help us decode the underlying meaning of Milani and Quigley's images.

Although a number of researchers have begun using alternative terms for the three metafunctions, I shall refer to the original terminology outlined by Kress and Van Leeuwen themselves. According to the visual social semiotics, the ideational metafunction allows us to explore the narrative in the image through its represented participants. It begs questions such as, what objects, people, and places are depicted in this image? What is the image about? What are the actions of those represented trying to tell me? An image's textual metafuction relates to its composition. Questions related to this function might be: How are the represented participants in the image arranged? What is this particular layout indicative of? What are the most salient (prominent) features in the image and what information are they conveying? Finally, with the interpersonal metafunction we go a step further to examine "the actions among all the participants involved in the production and viewing of an image" (Harrison, 2003, p. 52). Seemingly innocent elements such as the horizontal or vertical angles of the people and places represented or the 
distance from which they're portrayed can tell us a great deal about how we are meant to be addressed as an image's viewers (Kress \& Van Leeuwen, 2006; Harrison, 2003 p. 50-56). An analysis using these three metafunctions can reveal the underlying meaning of an image, as well as the specific methods (or "semiotic resources") the artist/designer has used to convey this meaning. Although Kress and Van Leeuwen's theory seems abstract in description, their concepts do begin to materialize once applied to actual images, which we will do shortly.

\section{METHODOOG: Aarification of "Sodilly Conscias At \&Design"}

As previously mentioned, Milani and Quigley's images can be seen as examples of socially conscious art and design conducted in collaboration with various bodies of the United Nations. Since according to Gillian Rose "semiological studies require extensive knowledge of the type of image the case study will examine," I think it necessary to clarify my use of this term before delving into the analysis ${ }^{1}$ (Rose, 2012, p.109). Although there is no universal definition for this type of work, it is based on the idea that designers have a unique gatekeeping role in society; they can shape both our physical and cultural landscapes, bring light to difficult and complicated issues, raise awareness on various forms of oppression that the general public might not be aware of, and allow us to reflect on work that is presented well and/or is full of elegance and beauty. Artworks and designs that are memorable, somewhat original, and combine form and function in an effective way will "create value on many levels" (Bowers, 2008, p.11). As such, the artists and designers who color our physical and cultural landscapes must determine not just the form of their visual messaging, but also its content and purpose in society. To put it simply, "the [artist's and] graphic designer's social responsibility is based on the wish to take part in the creation of a better

${ }^{1}$ By “design,” I am referring specifically to graphic design. 
world" (Bernard, 1997, para. 6).

On the spectrum of visual messaging, socially conscious art and design can be seen to operate well beyond the realm of commodity culture, which in Western society is a key feature of our contemporary postindustrial-capitalist climate. Until more recently, however, professional artists and designers had few lucrative employment opportunities beyond the realm of commercial design: "Despite important work in typography, illustration and poster design, until the thirties the graphic designer was, in the Western World, largely considered to be either a graphic artist or a commercial artist, adding an aesthetic dimension to visual images" (Frascara, Kalsi \& Kneebone, 1987, para. 16). According to Sturken and Cartwright, in any consumer culture...

...advertising [which is realized through commercial design] is central to the way in which commodities are given particular qualities and values that they do not have innately. A Marxist critique of capitalism [which as we have seen has seeped slightly into Kress and Van Leeuwen's own theory] understands advertising to be a means to create demands for products, which makes people buy more than they really need. That is to say that the exchange value of products, i.e. what they cost, is not aligned with its use value, or how useful that product really is within a given society (Sturken and Cartwright, 2000, p.199).

Since postindustrial capitalism defines the dominant power structures in the Western World today, these relations are subsequently reflected in the images that are produced in this context. As a result, advertising makes up a significant percentage of the "thousands of print and digital visual messages" the average person in the United States alone is exposed to on a daily basis (Bowers, 2008, p.21). Furthermore, besides being ubiquitous, these visual messages address audiences solely as consumers, often making overly conflated statements since their ultimate purpose is to convince viewers to buy products with questionable value and/or use. 
As of late, however, there has been a noted surge in the number of artists wishing to devote their skills to social causes in addition to (and occasionally instead of) selling commodities. Increasingly, artists and designers "are bringing attention to the idea that, in addition to using graphic design's persuasive qualities to market products, the visual language of design can be used as a communicative tool to inform the thoughts and actions of society for non-commercial facets of day to day living. By doing so, this intimate level of communication has the potential to create dialogues within society and to satisfy human needs, which can change the way people interact with each other and their surrounding environments" (Grigsby, 2003, p.7). Armando Milani himself has said: "At the start of the new century, I felt the ethical and moral need to dedicate part of my time to designing cultural and humanitarian posters...Today, I believe that we should worry about how to save our planet and ourselves, more than thinking about how to sell products. I'm worried and concerned about our future" (Milani, 2008, para. 2). Over time, many other artists and designers have had similar revelations, and have begun placing a greater emphasis on the content of their work, with considerations for "the impact that [it] has in the community and the way in which [this] content influences people" in general ${ }^{2}$ (Frascara, 1988, p. 21-22).

Socially conscious art and design goes beyond simple aesthetics to communicate certain "real-world" issues to its viewers. Through their work, socially conscious artists and designers demonstrate a keen awareness of the social/political/environmental matters they are addressing. According to design scholar Jorge Frascara: "Every time a graphic designer really wishes to achieve the objectives of the communication proposed, the cross-disciplinary nature of the

\footnotetext{
${ }^{2}$ Although it is beyond the scope of this MRP, readers may be interested in discovering more about the realm of social design which includes artifacts such as the 2000 First Things First Manifesto (a copy of which can be found in the appendix of this MRP), the magazine Adbusters, as well as the activity of 'culture jamming', which the United Nations itself has participated in through projects in collaboration with the international retailer the United Colors of Benetton.
} 
[design] profession becomes apparent" (1988, p 23). Though a captivating use of symbolism, Milani and Quigley both draw our attention to the issue of warfare, perhaps Milani more abstractly so than his contemporary. However it is important to see this type of work as only part of the solution to the issue and not the solution itself. While it would be naïve to assume that socially conscious art and design will solve the various concerns that it brings up, its main purpose is to bring people's attention to said concerns. Its visual rhetoric "attempts to coordinate social action. For this reason, [it] is explicitly pragmatic. Its goal is to influence human choices on specific matters that require immediate attention" (Howard, 2010, p. 173)

Successful socially conscious art and design raises awareness, since the first step to solving an issue is to identify it. At it's very best this type of work makes its viewers question the way we think about our environment and positively affects the way we behave in it. What this type of messaging has in common with Kress and Van Leeuwen's theory of visual social semiotics is the purposeful attention given to societal issues:

Social semiotics focuses on the syntactic relations between the elements of a visual text (e.g. people, objects, places, editing)...it aims to systematically reveal conventions in order to promote social change...Being able to systematically analyze texts, then, allows not only to renegotiate meanings that would be otherwise articulated "as fixed, irrevocable and natural" (Iedema, 2001, p. 201), but also to use resource inventories as tools for design promoting social change (Aiello, 2006, p. 99).

A social semiotic analysis of Milani and Quigley's images then will not only reveal their meaning and the ideology of the organization they were created for, it will also allow us to identify the semiotic resources that were utilized to make this particular kind of messaging effective. 


\section{METHODOLOGY: An Exploration of the Symbols in Question}

The concept of symbolism deserves our attention, since we have identified it as one of the semiotic choices at play in the visual rhetoric of Milani and Quigley's work. Semiotician, Charles Peirce, used the term symbolic sign to "indicate those signs in which there is no connection between the signifier (word/image) and the thing signified except that imposed by convention" (Sturken \& Cartwright, 2000 p. 368). According to Peirce, the very letters and words on this page are symbols, since their form has no physical resemblance or connection to their meaning. That is also to say that the association we make between this image: some point been socially constructed. Furthermore, Don Dondis states that "a symbol, in order to be effective must be seen...recognized... remembered and even reproduced" (Dondis, 1973, p. 72) The UN (and Milani and Quigley)'s use of these symbols rests upon their meaning having been reinforced for thousands of years, and on our ability to apprehend them. Indeed as stated by Sturken and Cartwright:

Images are produced according to social and aesthetic conventions. Conventions are like road signs; we must learn their codes for them to make sense; the codes we learn become second nature. Just as we recognize the meaning of most road sign symbols almost immediately, we read, decode, more complex images almost instantly, giving little thought to our process of decoding (2001, p. 25)

Although they are not the only pictorial symbols associated with the concept of peace (images of handshakes are often interpreted as peace symbols, as of course is Gerald Holtom's popular peace-sign design from the 1950's: $₫$ (Rigby, 1998, para. 13)), the UN's explicit and recurring reference to the dove and olive branch in its external communication materials shows Dondis' strategy of reinforcement-through-reproduction largely at play. Furthermore, Kress and VanLeewuen argue, that in their view, “signs are never arbitrary, and 'motivation' should be 
formulated in relation to the sign-maker and the context in which the sign is produced...Signmakers use the forms they consider apt for the expression of their meaning, in any medium in which they can make signs" (Kress \& Van Leeuwen, 2006, p. 8). In other words, the organization's usage of these symbols is not haphazard. Despite Sasaki's claim that the collaborations between artists and designers with the UN have been "relatively inconsistent," I would argue that the continuous decision to use the symbols of the dove and olive branch in visual communication materials for over 60 years is somewhat intentional. Nevertheless, how did the dove and olive branch come to be associated with the abstract concept of peace in the first place, and what do we even mean by the term "peace"? Evidently humans have been associating doves with a variety of concepts for quite some time now, and some associations go well beyond our modern interpretation of it as a peace symbol. According to Ted Andrews:

The dove has a tremendous wealth of lore and legend surrounding it. Most of it centers around all of the traditional feminine and mother symbols. In the Greek tradition, Aphrodite was born from an egg brooded by a dove...To the Slavs, the soul would become a dove at death. To the alchemist, it was a symbol of sublimation...to early pagans it was a symbol for the yoni or female sexual organs...To the Pueblo Indians it was also honored. Its feathers were often worn and used in prayer sticks (Andrews, 2003 p.133-134).

Although it has carried distinct meanings for different populations over time, it is worth noting the remarkable reach of and reverance given to the dove across such a wide variety of cultures. It is more difficult, however, to say why the associations described by Andrews above were initially made. A suggestion is that the popular animal symbol made its way across borders, "adapting itself to [the] local values" of each culture it reached (Rosenthal, 1994, p. 171). Peggy Rosenthal, a long time researcher on the subject of peace symbols claims "Like clichés and idioms, common images are so common that they go unnoticed by their contemporaries. [The 
histories of] visual images are even harder to track down than words because they are not catalogued" (Rosenthal, 1994 p.166). Rosenthal herself traces the symbolic roots of the olive branch back two millenia to the time of the Ancient Greeks. She describes how in the $5^{\text {th }}$ century $\mathrm{BC}$, olive wreaths were (for a reason she is unable to decipher) linked with "sacred honor for the highest human achievement" and awarded to members of society like Olympic athletes and model citizens (Rosenthal, 1994, p.170-171). As a symbol, the olive wreath was regarded as a (socially constructed) marker, distinguishing those with valuable societal traits such as, in the case of $5^{\text {th }}$ century BC Grecians, athleticism or an acute sense of civic duty. However for the Augustan Romans who greatly valued military defeat, Rosenthal argues that the same symbol came to connote military conquest: "It could then be worn proudly as honor for what Rome prized, military triumph" (Rosenthal, 1994, p.171). Wreaths were also presented to the conquered as the symbol of a peace pact, "although more often, a Roman peace pact was imposed on a defeated army after battle. Fundamentally, peace for the Romans meant military victory, and the fine points of pax Romana followed from that basis" (Rosenthal, 1994, p.165-166). Interestingly enough, although the olive wreath signified peace for the Augustan Romans long before it did for us, their conceptualization of peace seems much more authoritarian than the contemporary vision held by the United Nations. In remarks to the UN Security Council on post-conflict peacebuilding, current Secretary General Ban Ki-Moon stated:

Building peace is about much more than ending war. It is about putting in place the institutions and trust that will carry people forward into a peaceful future...Decades of international experience have taught us that, while every case is unique, certain types of support are almost always needed. Time and again, war-ravaged people have asked us to help them establish security and safety, restore basic services and core Government functions, support a political transition and jump-start economic recovery (Ki-Moon, 2009, para. 3). 
For the United Nations, then, peace is more than a valorized ideal blankly projected onto an image. It is a tangible, real-world, ongoing process, and as we shall see Milani and Quigley's work pays tribute to this ideology of peace beautifully.

Tracing the two symbols forward in time, the dove and olive branch are said to have appeared together for the fist time in early Christian iconography. One of the most common (though not the definitive) explanations of how came to symbolize peace brings us to religious scripture:

We might know the myth of the flood in Genesis, with the dove sent out by Noah returning with a freshly plucked olive leaf in its beak as a sign that the waters had receded enough for the renewal of life to begin. We might also recall that God revealed his forgiveness by means of a rainbow, as a "sign and a covenant between me and the earth," but what we still do not know who first used these images as peace symbols (Ribgy, 1998, para. 9).

In this context we can again see the dove operating symbolically as a messenger of peace, a vessel for divine communication between God and Noah. However, Riby's last sentence is rather telling, and suggets that the first associations made beetween this symbol not—and perhaps should not—be attributed to one specific time, place, or culture. As we can see, both symbols, whether shown together or apart, have international roots in classical and religious traditions. Furthermore, Rosenthal argues that their cultural origins are further outshadowed by the staying power they have achieved in representing peace across cultures and over time. The symbols are still alive today because they still speak to us:

We still see peace as a pact (in peace treaties), and we still see peace as reconciliation (in negotiations and conflict resolution). Even more-and this is our half century's special development, an international consensus voiced through the $\mathrm{UN}$ - we need to see these two meanings of peace as one [...] The international 
community's ideal peace pact today truly reconciles conflicting parties, because we understand that only a reconciling peace can last [...] The generic green branch's archetypal meaning enlivens the conventional olive peace symbol for us today. We seem to need to see peace as alive and well and growing (Rosenthal, 1994, p. 175176).

The dove too can indicate this concept of renewal, since according to Andrews, "the dove's song is its most distinctive characteristic... Out of its mourning, it invokes new waters of life. Its song should remind us that no matter what our life conditions, new waters and new life are still possible" (Andrews, 2003, p. 134).

The near primal universality of the dove and olive branch as symbols allows them to communicate across linguistic and cultural barriers, reaching a truly cross-cultural audience. This has made them ideal for use in the visual communication materials of an organization like the UN, founded on the fringes of a Second World War and "committed to maintaining international peace and security, developing friendly relations among nations and promoting social progress..." (“The united nations", 2012, para. 1). Furthermore, on a professionally practical note, communication requires sharing symbolic codes; and while designers need not refer to stereotypical images to get their messages across, they still cannot ignore those codes and symbols that have come to be known and accepted by the public. Instead, designers can work alongside the public to expand this set of codes, and to "improve its visual and conceptual language as much as possible, without breaking the communication link" (Frascara, 1988, p. 20). Knowing the origins of these symbols and their histories gives us greater insight into their unique adoption by Milani and Quigley in their work for the UN, which I will now discuss in further detail. My analysis shall be arranged according to the three aforementioned metafunctions, ideational, textual, and interpersonal. 


\section{ANALYSIS OF IMAGES \& FINDINGS/INIERPRETATIONS}

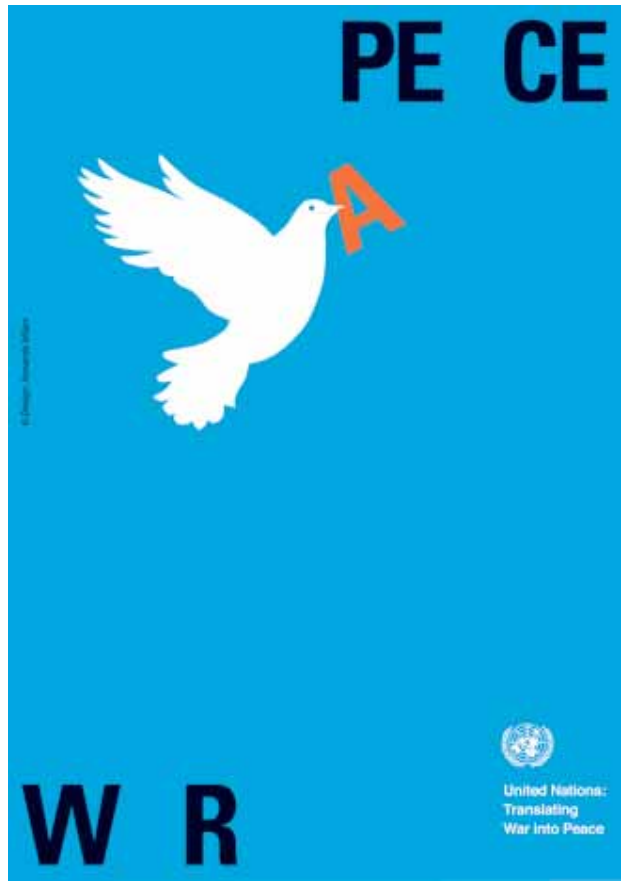

Figure 1: Translating War Into Peace (poster) Armando Milani, 2004

\section{Translating War Into Peace (poster) - Armando Milani, 2004}

Armando Milani is an award-winning Italian graphic

and for his collaborations with "humanitarian agencies and cultural institutions" in the design and production of their communications materials (Samara, 2007 p. 87). An acclaimed member of the Alliance Graphic Internationalle, Milani's portfolio includes logos, book covers, and cultural posters just to name a few items. Over the years his works have addressed several important social issues ranging from the AIDS epidemic in Africa (Samara, 2007, p. 89) to the dangers of smoking (Milani, 2011).

His Translating War Into Peace poster was designed for the UN in 2004 and was in the following year, used to commemorate the organization's $60^{\text {th }}$ anniversary—hardly a small feat for an already accomplished designer. Furthermore, Milani's design has been adapted into various forms of merchandise including watches, mouse pads, and magnets that are still being sold by the UN today, some eight years after the image was first produced. Determining why this work has resonated so much with the UN that they have reproduced it in this manner requires analyzing its visual components to understand its underlying meaning. 


\section{Ideational Metefundion}

According to the theory of visual social semiotics, a look at the ideational metafunction of this image will reveal the people/places/objects represented in it, as well as how these elements are interacting with one another to create a narrative. Using Kress and Van Leeuwen's visual grammar, we can see that the represented participants in this image are an abstracted white dove facing right, the letters WR, A, and PECE in groups, and the UN's logo on the bottom right hand side. Below this logo in small font is the organization's name along with the title of the poster directly beneath it: Translating War Into Peace. The words "Design: Armando Milani” appear in tiny black copy along the vertical left hand side of the image. The most easily recognizable figure in Milani's poster is the dove, which should immediately conjure up thoughts of peace in viewers' minds. Because this association to peace has been (as mentioned) continuously reinforced over time, the designer is able to reference it without worrying that its meaning will somehow get lost in translation. Milani's image is also quickly recognized as being in English and so we "know" to read it from left to right. Even form a purely visual standpoint, the dove's body also acts as a diagonal vector, guiding our eyes on a pathway from the bottom left to the top-right hand of the image. A vector is any form in an image that conveys a sense of directionality or "points at things" (Kress \& Van Leeuwen, 2006, p.55). Kress and Van Leeuwen introduced this term as the component of their visual grammar which is equivalent to an action verb. The real and/or virtual lines between the formal elements in an image function similarly to how relations are described in Hallidayan grammar, where we would use the terms "actor and goal" to indicate some sort of action (Forceville, 1999, p.165). How vectors relate to one another is what creates the narrative in an image, distinguishing the role of each formal element. In Translating War Into Peace, the dove can be considered our "actor," the represented participant from which the vectors emanate (Kress 
\& VanLeewuen, 2006 p.63). Besides the front of its body, the dove's wings can also be considered vectors, aimed upwards to represent the bird being in mid-flight. On a conceptual level, this "activation" of the symbol could connote process, activity, and dynamism. Although the dove is what initially draws our attention, it is aligned in a way that makes it part of an even larger narrative, rather than a lone-standing static figure—-this tells us that the narrative we are describing is a transactional one. According to Kress and VanLeeweuen the Actor in such a transactional process is the instigator of movement-a verbal paraphrase of this process might take the form of a transitive verb, for example "a verb that takes an object (e.g. 'transport' or 'send'...)" (2006, p.64). Looking closely into the dove's beak we can see what it is that is being transported: where normally an olive branch might be seen, Milani has placed the letter A.

\section{Textual Metafundion}

This takes us to the textual metafunction, which requires examining the various compositional elements of an image. According to Kress and Van Leeuwen, "textual or compositional meanings...integrate representational and interactive elements to compose a meaningful whole" (Almeida, 492). Milani's piece is simply, purposefully, and powerfully laid out. We can immediately note that the poster is multimodal, meaning it has integrated both words and images to get its message—which we have yet to fully decode—across (Kress \& Van Leeuwen, 2006, p.177). The dove, a sharp white figure against the blue of the poster is arguably the most salient (i.e. prominent) feature, capturing our attention first. Blue also happens to be the color of the United Nations flag, so this choice was most likely intentional. The complementary orange chosen for the A in the dove's beak ensures that it too stands out, and this initial focus the top right-hand side of the image leads our eyes to the letters PE_CE. A sub-concept of the Gestalt theory of perception suggests that when we read familiar words, we process them as whole images rather 
than by looking at each individual letter (Dondis, 1973, p. 39). Based on this idea, we would see the letters PE_CE as intending to mean PEACE, but our minds would have us searching for the noticeably absent A. By now we have connected some (if not all) of the figurative dots. On the bottom left side, we see the letters W_R, and finally Milani's literal narrative can be understood: The dove ("actor") has taken the letter A away from WAR and intends to use it to complete the word PEACE (this is its "goal").

We can read further into the compositional meaning of Milani's poster using a semiotic resource of compositional structuring known as information value, in which "the placement of [represented participants] allows them to take on different information roles" (Harrison, 2003, p. 57). If we were to place an imaginary vertical line down the middle of the poster, it would create a left/right divisionary plane. According to Kress and Van Leeuwen, the left hand side would contain information that is "given," and the right information that is "new": "For something to be Given means that it is presented as something the viewer already knows, as a familiar and agreedupon point of departure for the message. For something to be New means that it is presented as something which is not yet known [...] hence as something to which the viewer must pay special attention" (Kress and Van Leeuwen, 2006, p 187). For me this can also be interpreted as giving the image a sense of temporality, with the left side implying what has come in the past and the right implying what may come in the future. In Milani's poster, the dove has (past-tense) taken the A out of WAR and is depicted mid-motion on its trajectory towards PEACE. Although the words on both margins are incomplete, the dove delivering the letter $\mathrm{A}$ is placed somewhat in the middle, which signifies that this action is taking place in the present. Moreover, figures depicted in the center (as opposed to the margins) of an image "provide the nucleus of information to which surrounding elements are subservient" (Harrison, 2003, p, 57), and this notion is especially 
applicable to Milani's design. Finally, the concept of information value also posits that in a horizontal division of the compositional plane, "the upper section tends to make some kind of emotive appeal and to show us 'what might be'; [while] the lower section tends to be more informative and practical, showing us "what is" (Kress \& Van Leeuwen, 2006, p. 186). In this case we could read WAR as what is, and PEACE as what might potentially be.

\section{Interpersonal Metafunction}

The final metafunction, interpersonal, allows us to carefully examine the elements at play in the production of this image and how they affect our process of viewing it. The graphic quality, bold lines and fonts, and minimalist yet vibrant color palette of Milani's image gives it a playful but not overtly cartoonish vibe. The image can be called abstract, if we see abstraction as "the reduction of multiple visual factors to only the essential and most typical features of what is being represented" (Dondis, 1973, p. 71). This decision to use letters and symbols against a saturated blue backdrop (rather than "realistically" depicting people and places) allows viewers to project the scenario of translating war into peace into any of the unfortunately many violent conflicts taking place around the world. Furthermore, the producers' names (Milani's in black on the left side and the UN logo on the bottom right in white) are presented as secondary information, giving precedence to the image and its message. Although this "backgrounding" can be considered part of the textual metafunction, "putting the message first," so to speak, grants the image more power and communicates a certain level of humility in how we are being addressed as an audience, making it also part of the interpersonal metafunction. Based on the analysis of these three metafunctions, my personal reading of Translating War Into Peace suggests that it uses symbolism in a transactional narrative to abstractly represent the ideology and ongoing work of the United Nations - the concrete process of not just ending war as Ban Ki Moon tells us above, 
but of taking resources associated with war and using them to build peaceful infrastructures. The word "translating" in the title of the image also implies multilingualism, and subsequently cooperation, understanding, and transformation, all necessary criteria for the creation of a lasting peace as called for by the United Nations.

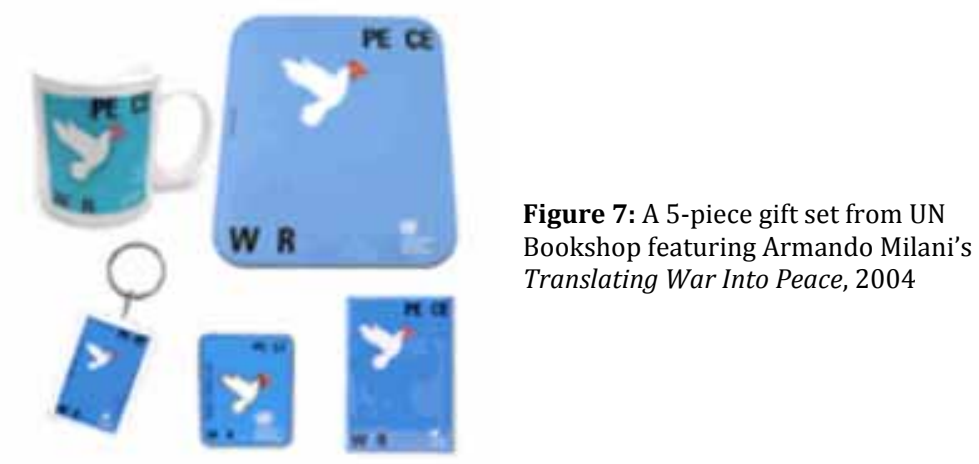

The simplicity of Milani's design, in its compositional layout, its clever use of symbolism, and in its choice of English as its communicatory language, implies a desire to reach as broad an audience as possible. This is also evident in the UN's decision to reproduce his poster into other formats. Although the poster itself has been cancelled as a sale item, audiences for whom Milani's image has struck a nerve can purchase it in the form of a mug, mouse pad, keychain, or even a magnet. In fact, a five-piece gift set available online at the UN Bookshop retails at US \$23.95 (Figure 7). Interestingly enough, these are all functional items of habitual use that would confront us with Milani's image/message each time we take a coffee break, use a mouse, unlock a door, or post something on the fridge. However what distinguishes the commodification of Milani's image from a traditionally advertised product is that the bottom line of being "sold" on the producers' message is not bankable profit. If buying Milani's design is still not an option, Translating War Into Peace can also be found circulating digitally and freely on the internet: the image is featured on several design blogs, Milani's own personal site (along with his other work), and, as previously 
mentioned, on the official website of United Nations Bookshop. Moreover, the meaning of Milani's image does not seem to be affected by this adaptation into various formats: Though originally created as a poster, the image's basic design elements (namely its composition) are not greatly altered in conversion. While technical features may vary to accommodate each new medium — the sizing of the dove, lettering, and logos, etc.- their orientation remains the same, and as a result so does the transactional narrative. It can be assumed that viewing the image on a mouse pad as opposed to a poster does not greatly alter the producers' message.

Just how much this message has inspired people or motivated them to some kind of action in the achievement of a lasting peace is a much more difficult supposition to make-and this could be said of most socially conscious art and design. Unlike in advertising, the impact of such messaging cannot be measured primarily in dollars. However, according to Jorge Frascara, if socially conscious artists and designers wish to be seen as problem solvers they must concern themselves with the results of their work, gauging their success based whether or not they have met the objectives that generated the need for their designs in the first place:

In terms of practice [...] the experts required for this task may vary from one professional area to another, but, in general, they should presumably come from the fields of marketing, sociology, psychology, and education, disciplines whose main concerns are the behavior of individuals and groups, and the problems of interpreting, quantifying, and qualifying information, as to a greater or a lesser extent, applying the information to practical ends (Frascara, 1988, p. 25 - 26).

Although Frascara's point is valid, it is beyond the scope of this MRP to detail how this image has impacted people's views on the UN, war, and/or peace on a mass scale. The organization's decision to produce Milani's work in multiple formats is, however, one sign of its significanceas is the fact that it is still being reproduced and disseminated today. What we can also deduce is that so long as the United Nations is dealing with the concrete issues of ending war and tying to 
build sustainable infrastructures for peace, the image will continue to resonate, representing the organization's ideology to all those who come across it. According to Milani himself: "As designers, we certainly don't have the power as politicians have, to change the world. But, I believe that it is our duty to denounce these dramatic problems and induce people to reflection and reaction" (Broda, 2011, para. 1).

\section{Pablo Picasso's Peace Dove by Palestinian Children at Jericho - Spectral Q Project John Quigley in cooperation with United Nations Relief and Works Agency (2011)}

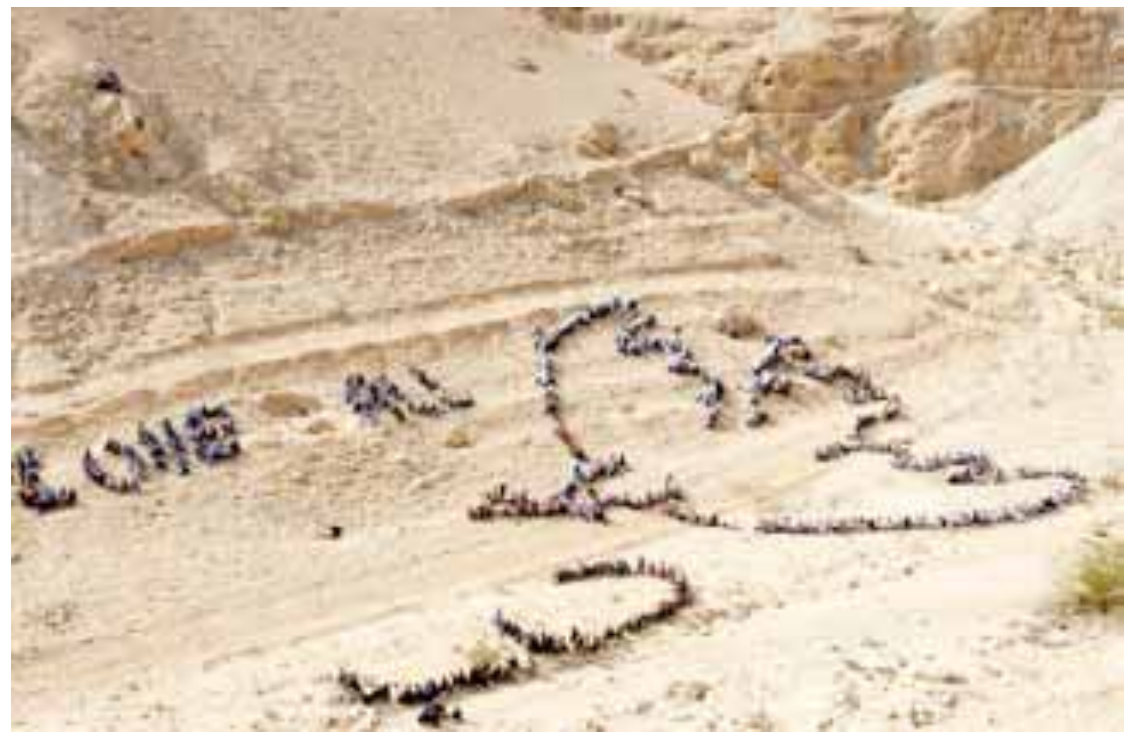

Figure 2: Pablo Picasso's Peace Dove by Palestinian Children at Jericho, (SpectralQ Aerial Art project)

John Quigley in collaboration with United Nations Relief Works Agency (UNRWA), November 2011

Another visionary with a propensity towards "reflection and reaction" is the educator, environmental advocate, and international artist John Quigley. For a recent project conducted in collaboration with the United Nations Relief and Works Agency (UNRWA), Quigley travelled to one of the world's oldest inhabited cities, Jericho, and rallied just over a thousand Palestinian school children to stand in formation of a symbolic peace dove, as well as to spell out the words "love" and "love all" in Arabic and English respectively. Although his process was partially documented on video, the project is also depicted in several aerial photographs displaying the message from above. Quigley coined the term SpectralQ Aerial Art to describe this type of 
messaging, and he defines it on his website as "the creation of forms upon the land whose true identity is only revealed from an aerial perspective" (Quigley, 2012, para. 4). According to Quigley, this particular type of message-making partially evolved from the Human Pointillism movement of the early $20^{\text {th }}$ century in which "photographers Mole and Thomas began traveling to military bases and creating massive installations of patriotic icons such as the Statue of Liberty, the Liberty Bell, Woodrow Wilson's profile, the Marine Corps Seal and many others" (Quigley, 2012 para. 4). Mole and Thomas used military men as the "medium" for this political messaging, their reasoning being that standing in formation was an activity they were quite used to in the army. Quigley's thought, however, is that everyone can be artist, and his inclusive type of aerial messaging operates within this framework:

Because this work involves thousands of people I [see] the opportunity to not only send powerful messages but also to creatively activate the participants to see themselves in a new way. The participants are not extras on a film shoot. They are never paid to do this [...] They have to believe in the message enough to spend several hours of their time sitting, laying, kneeling, or standing in a giant form with their bodies most likely touching a stranger. They become co-creators of a momentary human sculpture that is documented for the world to see then dispersed to the wind like a Tibetan Sand Mandala. The experience involves both precision and chaos and hopefully above all FUN. We get to play with each other while embodying a message to the world about what matters most to us. And we do it all through direct experience in the presence of each other rather than virtual electro reality. My mission has been to create a world of Aerial Artists by sparking participants to become creatively activated and to connect with each other (Quigley, 2012, para. 3).

Quigley's project in Palestine can be considered an example of arts-based peacebuilding, with the term peacebuilding referring to "efforts to prevent, reduce, transform, and help people recover from violence in all forms, at all levels of society, and in all stages of conflict" (Shank \& 
Schirch, 2008, p. 2). Generally, art as a communicative tool has no specific allegiance and can be used by anyone to promote anything, including positive or negative values. Oftentimes, art can simply be created "for expressive purposes without a larger goal of promoting any specific outcome" (Zelizer, 2003, p.66) However, more and more, art is being seriously considered as a unique tool in peacebuilding to counter conflict in societies at interpersonal, communal, national and global levels, even by the United Nations (Shank \& Schirch, 2008, p.11). Whether during conflict or afterwards in post-conflict peacebuilding efforts, community based arts processes can be seen as an effective means with which to bring together different identity groups to share common cultural experiences, increase awareness about the negative effects of a conflict, and create a platform for self expression through engaging communities in creative-oriented projects (Zelizer, 2003, p.62). Quigley's tagline for SpectralQ art is “Collaborative Art for the Common Good," and his general aim is to bring global awareness to various human rights, health, social justice, and environmental issues. His international body of work, over a hundred and fifty pieces strong, is a clear reflection of this. Compared to Milani's abstract yet succinct designs, Quigley's work is slightly more multilayered, since Aerial Art has as much to do with the final product as the meaningful process it took to get there. The full meaning behind any of Quigley works often requires further exploration on the part of the viewer. ${ }^{3}$

The photograph in Figure 2 can be said to represent the interests of both Quigley and the United Nations as co-image producers. For simplicity's sake, however, I shall refer to the work as Quigley's. While our focus will be on an aerial image of this project, it is worth mentioning that

\footnotetext{
3 Because there are several images of this particular project available online, it was necessary to determine which depiction best captures it, since each has been framed in a particular manner. In the spirit of partnership, my diplomatic resolution was to examine the image provided by the UN press release describing the project-since it was after all a collaborative effort (as articulated in the work's title).
} 
viewers have easy online access to a three-minute video released by UNWRA showing the process as well as the final product. Film is another medium in which Quigley's works can create an impact because viewers gain intimate view of the participants involved as well as of the project taking shape. However the work in Quigley's own portfolio is shown exclusively through photography, which according to Robert Hairman and John Lois Lucaites "activates available structures of feeling within the audience, keys the emotional dimension of an event, and bonds audience, artistic practice, representational object, and social context affectively. Thus photography operates not just as a record of things seen but also as a way of seeing that is attentive to what is aesthetically distinctive, socially characteristic, and emotionally evocative" (Hairman \& Lucaites, 2007, p.35-36).

\section{Ideational Metefundion}

Our analysis of Pablo Picasso's Peace Dove by Palestinian Children at Jericho begins again with the ideational metafunction, describing the represented participants depicted in the image and how their interaction forms a narrative. Right away we notice the backdrop of the photograph is a desert valley on which numerous little figures have gathered into various formations. Like Milani, Quigley's arrangement is also multimodal, utilizing both images and text. On the far right of the photograph we see the symbol of the dove. Facing left, the dove seems to have something, which we can assume to be an olive branch, in its beak. Below the branch is written "love" in large Arabic script, and above it on the far left "LOVE ALL" is spelled out by the figures in English capital letters. Unlike Milani's image, however, Quigley's dove is nontransactional; “The action in a non-transactional process has no 'Goal', is not 'done to' or 'aimed at' anyone or anything. The non-transactional action process is therefore analogous to the intransitive verb in language (the verb that does not take an object)" (Kress \& Van Leeuwen, 
2006, p.63). Nevertheless, one could argue that the "actors" in Quigley's image are the children who make up the composition, and that their "goal" is the message itself, which is transmitted through the composition (which we shall discuss shortly). It is also worth noting that the title of this work provides us with a fair amount of information that we might not be able to infer by looking at the image alone. However, since images of Quigley's projects circulate primarily online, it is unlikely that we would come across one without some sort of surrounding copy or a hyperlink to give it context. As a result I believe it is fair to use this information in our analysis. Furthermore, Gillian Rose claims: "Crucially, most communication involves more than one mode: hence social semiology emphasizes the multimodality of semiotic design (and social semiotics is sometimes called multimodal research)" (Rose, 2012, p.139). This statement is intended to remind us that images rarely stand on their own, and that most have some sort of accompanying semiotic resources to help us understand their overall meaning. Quigley's title, for example, informs us that the location for the project was Jericho (located in the West Bank, Palestine), and it identifies the small figures as Palestinian school children. The title also makes a clear reference to Pablo Picasso. This is because the dove Quigley has used for his composition is based on a sketch made by the famous Spanish artist some six decades ago (Figure 8).

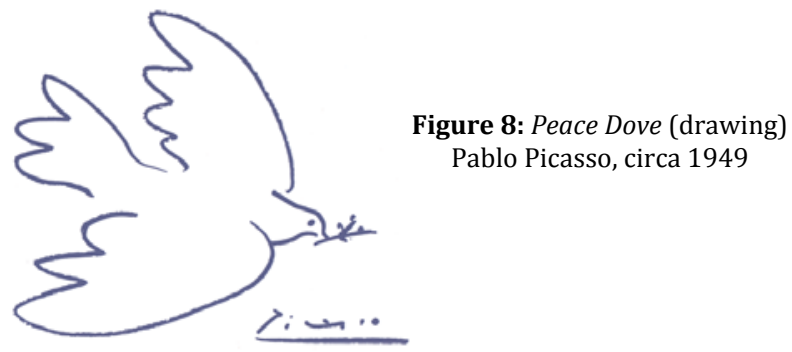

In the realm of socially conscious art, Picasso himself might be best known for his famous 1937 painting Guernica, an imitation-tapestry of which is hung in the United Nations Building in New York ("Guernica”, 2012, para. 33). The painting is in black and white and employs a cubist 
style with distorted and fragmented elements. Its subject matter, the atrocities of war, are clearly meant to condemn the slaughter of innocent civilians during the Spanish civil war-specifically the bombing of the city of Guernica, in which hundreds of innocent civilians-mostly women and children-perished ("Guernica”, 2012, para. 17). With his modernist visual language, Picasso became well known as the creator of avant-garde works "that repudiated fascism" well before the end of the Second World War, or the founding of the United Nations for that matter (Feeser, 2003, p.37). Interestingly enough, the tapestry in the UN Building was controversially covered up during Colin Powel's February 5, 2003, presentation to the Security Council on America's case for war against Iraq. Although it was claimed that this was done for the cameras, it could be argued that covering up the image had less to do with technical circumstances than the power of its anti-war message (Walsh, 2003, para. 6). Picasso's doves came to prominence when they began appearing on official peace communication materials after the Second World War, including on a poster for the 1949 World Peace Conference held in Paris (Figure 9).

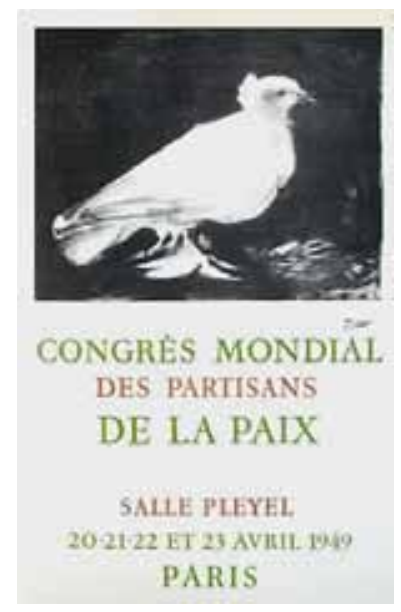

Figure 9: World Peace Congress Poster Pablo Picasso, 1949

Subsequently stylized into the simplified, abstract, linear sketches like the one used in Quigley's composition, Picasso's doves soon began appearing in the materials of the Parti Communiste Français (PCF) to which the artist belonged (Feeser, 2003, p. 33). For the 
communist-sponsored World Peace Congress held in Warsaw in 1950, streets, shops ports and railway stations were all decorated with flags, streamers, and posters displaying the artist's doves (Deer, 2002, p. 465). The fact that the animal has been able to stand for peace in societies with varying political leanings once again highlights the universality of this symbol. Quigley has made reference to Picasso's doves in at least one other of his works, but it is difficult to speculate as to the significance of these gestures. Although the ultimate reason for his homage is possibly more profound, Picasso's simple linear style certainly works well for the types of compositions Quigley's Aerial Art requires, which leads us to examining the textual metafunction of the image at hand.

\section{Textual Metafunction}

While the symbol of the dove and olive branch takes up the most space in the Quigley's composition, the size of the words in both languages is rather prominent as well. Although the human figures are hard to distinguish individually (and this might be due to poor image quality), their varying heights and colorful clothes contrast well against the sand of the rocky desert, adding further to the photograph's organic quality. The overreaching message is clear and direct: Love all. The fact that it is also written in Arabic pays respectful tribute to the land and native language from which the message is being sent.

\section{Interpersonal Metafundion}

Because the composition in this image is so straightforward, the meat of Quigley's message can be found by further examining its interpersonal metafunction-or more specifically, how he (and the UN as image producers) address us as an audience. Although the most prominent figures in the composition are technically the dove and olive branch, the project's most salient feature is its use of human bodies as a medium. The use of abstracted non-human forms to 
represent peace allows such symbols to operate globally, not referring to any one specific war, but all human conflicts in a sense. Furthermore, "the gentleness of the animal [emblem] marks a distance from wartime violence, even while it obliquely acknowledges that violence in its erasure" (Feeser, 2003, p. 46). Quigley's technique of using human bodies to form peace symbols and then having them photographed from above subverts this idea; it challenges viewers to literally look beyond these symbols to actually see those who are impacted by the violence of war, in this case the children of Jericho (and perhaps all children in general). As in Milani's work, the symbol of the dove and olive branch is not the sole carrier of meaning but is part of a grander narrative: The symbol is part of the larger message of seeing peace as a process that involves the plight of actual people in actual localities - in this particular case, Palestine. In a press release from UNWRA regarding the project, Quigley was quoted as saying: "These kids are planting seeds of peace into the heart of the Middle East conflict. They deserve the kind of positive future we wish for all children" ("UN news centre", 2011, para. 4). Because the aerial photograph is taken from quite a long distance, we cannot identify each individual child, nor would this make sense in the context of Quigley's work. However what does clearly come across is the children's willingness as individuals to come together and form this unified message-which can also be read as an emotional plea.

As an example of socially conscious art, Quigley's technique is exceptional. Aerial Art requires that its subjects be photographed from a high vertical angle for a functional purpose, in order that the collective message can be seen. According to visual social semiotics, this orientation also places the viewer of such an image in an empowering position. For Kress and Van Leeuwen, the top-down angle is one of "maximum power". Their grammar ascertains that this particular perspective is oriented towards theoretical or objective knowledge, and that it 
"contemplates the world from a god-like point of view" (Kress \& Van Leeuwen, 2006, p.145). Just how much this empowerment (potentially brought on by our bird's eye view of children in Jericho asking us to "LOVE ALL") inspires us to take action is largely subjective. As with Milani's work, the aim of such art is not to solve the issue being represented, but to (among the other goals discussed above) draw attention to it in a way that might inspire reflection, and subsequently, action. According to UNRWA Commissioner-General Filippo Grandi: "The world needs to sit up and listen to the youth of this region. Their message of peace is essential. It is the voice of the next generation" ("UN news centre", 2011, para. 5). 


\section{FNAL THOUGTS}

This MRP examined the ideology of the United Nations as manifest through their external visual communication materials_-namely through a visual social semiotic case study of two works developed in partnership between international artists Armando Milani and John Quigley with various UN bodies. In a visual culture largely dominated by profit-driven design, my aim was to shed light on the necessity to produce, analyze, and measure the value of socially conscious art and design projects, since such partnerships with organizations whose bottom line is not financial revenue can allow for the creation of truly meaningful work that addresses viewers not solely as consumers, but as humanitarians. While a number of scholars have used Kress and Van Leeuwen's theory to shed light on the visual semiotic resources employed in capitalist and educational contexts, further analyses of art and design produced in non-for-profit contexts can equip designers wishing to engage in this type of work with the analytical mindset and semiotic resources available to produce strong bodies of work.

With regards to the UN's visual corpus, the use of pictorial symbols to communicate allows artists and designers to tap into a reservoir of what psychologist Carl Jung calls "representations of 'eternal truths' with archaic roots, but which [can] still retain something of their original power or 'spell' in the modern world" (Rigby, 1998, para. 23). The more universal a symbol, the more likely it is to speak to a wide array of cultures, and as we have seen, the dove and olive branch have their symbolic origins in various parts of the world, and their current associations with peace have evolved out of both classical and religious archaic traditions. Founded in 1945, the United Nations has been using these symbols in its visual communication materials for international audiences since its inception (including, as we've seen, in the organization's very logo). However, Milani and Quigley's aforementioned pieces use these symbols in a manner that goes 
beyond simply branding the organization. Their semiotic choices allow for a visual rhetoric that gives viewers a "bigger picture" of peace. As images, they are undoubtedly successful since whether a design outcome reaches its potential has much to do with its ability to efficiently speak to its target users, while at the same time being aware of cultural idiosyncrasies. A well thought out design uses culturally appropriate graphics that are intended to resonate with the various ages, genders, ethnicities, contexts, socio-cultural and political values and visual and media literacy of its audiences: "When a design resonates with the culture(s) of users it uses culturally appropriate aesthetics that are gender-fair, age appropriate, multicultural and intellectually and technologically accessible" (Bennett, 2010. p.5).

Based on our analyses, Milani and Quigley's works Translating War Into Peace and Picasso's Peace Dove...Jericho meet all of these criteria. It is difficult (and perhaps unnecessary) to determine whether inspiration to use the symbols in their images came from the artists themselves or from some sort of aesthetic mandate by the UN. Nevertheless, these collaborations have resulted in truly unique materials of socially conscious art and design. A visual social semiotic reading of Milani and Quigley's creations in the respective media of graphic design and arts-based peacebuilding shows that they challenge viewers to look beyond the dove as a superficial symbol to see the greater narrative of their work-a "bigger picture". The designer and artist have managed to visually manifest the UN's ideology of peace. We have determined that this ideology requires taking resources away from war and using them to build sustainable nonviolent infrastructures, as well as acknowledging the real-world plight of those who are affected by peace's absence. Both designer and artist have employed the symbols of the dove and olive branch in a manner that is meant to inspire further reflection (and potentially even action) on the part of the viewer. 
As artists and designers, Milani and Quigley are the "creators of experiences". These experiences can involve interactions or environments that shape a moment or series of encounters, which in turn can create a lasting impression or desired response. Building a sense of participation, ownership, or loyalty to an idea is often a design goal" (Bowers, 2008, p.10). Through the dissemination of their images Translating War Into Peace and Picasso's Peace Dove...Jericho, the UN is undoubtedly reaching out to build a sense of loyalty to their vision of peace. As Andrew Rigby tells us: "While many of us lack the courage and the single-mindedness of past and present generations of direct activists, prepared to risk imprisonment in their struggle to rid the world of weapons and structures of violence, we can still do our little bit. We can wear the badge, display the emblem, and signify our affiliations" (Rigby, 2003, para. 27). By using their unique skills to visually proclaim the values of humanitarianism in the public sphere, artists and designers undoubtedly contribute to the strengthening of a culture of peace. 


\section{APPENDIX 1 - FRST THNGS FRST 2000}

\section{(Original manifesto written by designer Ken Garland in 1964)}

\section{A design manifesto published jointly by 33 signatories in: Adbusters, the AIGA journal, Blueprint, Emigre, Eye, Form, Items Fall 1999 / Spring 2000}

We, the undersigned, are graphic designers, art directors and visual communicators who have been raised in a world in which the techniques and apparatus of advertising have persistently been presented to us as the most lucrative, effective and desirable use of our talents. Many design teachers and mentors promote this belief; the market rewards it; a tide of books and publications reinforces it.

Encouraged in this direction, designers then apply their skill and imagination to sell dog biscuits, designer coffee, diamonds, detergents, hair gel, cigarettes, credit cards, sneakers, butt toners, light beer and heavy-duty recreational vehicles. Commercial work has always paid the bills, but many graphic designers have now let it become, in large measure, what graphic designers do. This, in turn, is how the world perceives design. The profession's time and energy is used up manufacturing demand for things that are inessential at best.

Many of us have grown increasingly uncomfortable with this view of design. Designers who devote their efforts primarily to advertising, marketing and brand development are supporting, and implicitly endorsing, a mental environment so saturated with commercial messages that it is changing the very way citizen-consumers speak, think, feel, respond and interact. To some extent we are all helping draft a reductive and immeasurably harmful code of public discourse.

There are pursuits more worthy of our problem-solving skills. Unprecedented environmental, social and cultural crises demand our attention. Many cultural interventions, social marketing campaigns, books, magazines, exhibitions, educational tools, television programs, films, charitable causes and other information design projects urgently require our expertise and help. 
We propose a reversal of priorities in favor of more useful, lasting and democratic forms of communication - a mindshift away from product marketing and toward the exploration and production of a new kind of meaning. The scope of debate is shrinking; it must expand. Consumerism is running uncontested; it must be challenged by other perspectives expressed, in part, through the visual languages and resources of design.

In 1964, 22 visual communicators signed the original call for our skills to be put to worthwhile use. With the explosive growth of global commercial culture, their message has only grown more urgent. Today, we renew their manifesto in expectation that no more decades will pass before it is taken to heart.

\section{Signed:}

Jonathan Barnbrook

Nick Bell

Andrew Blauvelt

Hans Bockting

Irma Boom

Sheila Levrant de Bretteville

Max Bruinsma

Siân Cook

Linda van Deursen

Chris Dixon

William Drenttel

Gert Dumbar

Simon Esterson

Vince Frost

Ken Garland

Milton Glaser

Jessica Helfand
Steven Heller

Andrew Howard

Tibor Kalman

Jeffery Keedy

Zuzana Licko

Ellen Lupton

Katherine McCoy

Armand Mevis

J. Abbott Miller

Rick Poynor

Lucienne Roberts

Erik Spiekermann

Jan van Toorn

Teal Triggs

Rudy VanderLans

Bob Wilkinson

....and many more 


\section{REFERENCES}

Aiello, G. (2006). Theoretical advances in critical visual analysis: Perception, ideology, mythologies, and social semiotics. Journal of Visual Literacy, 26(2), 89-102.

Aiello, G., \& Thurlow, C. (2007). National pride, global capital: a social semiotic analysis of transnational visual branding in the airline industry. Visual Communication, 6(3), 305344. doi: $10.1177 / 1470357207081002$

Almeida, D. (2009). Where have all the children gone? a visual semiotic account of advertisements for fashion dolls. Visual Communication, 8(4), 481-501. doi: $10.1177 / 1470357209343374$

Andrews, T. (2003). Animal-speak: The spiritual \& magical powers of creatures great \& small. (1 ed.). St. Paul, USA: Llewellyn Publications.

Bennett, A. (2010). Teaching design standards in a socially conscious age. Transformative Dialogues: Teaching \& Learning Journal, 4(2), 1-6.

Bernard, P. (1997). The social role of the graphic designer. Essays on Design I: AGI's Designers of Influence, London 1997, Retrieved from http://backspace.com/notes/2009/09/thesocial-role-of-the-graphic-designer.php

Bombing of Guernica. (2012, July 23). In Wikipedia, The Free Encyclopedia. Retrieved 12:27, June 27, 2012, from http://en.wikipedia.org/w/index.php?title=Bombing_of_Guernica\&oldid=503742662

Broda, J. (2011, September 11). [Web blog message]. Retrieved from http://bojoda.com/tag/armando-milani/

Deery, P. (2002). The Dove flies east: Whitehall, Warsaw and the 1950 world peace congress. Australian Journal of Politics \& History, 48 (4), 449-468.

Feeser, A. (2003.) Picasso and Éluard : Kinder, gentler heroes for war-damaged France. Men and Masculinities : 6 (1), 31-53. doi:10.1177/1097184X02250837

Forceville, C. (1999). Educating the eye? kress and van leeuwen's reading images: The grammar of visual design (1996). Language and Literature, 8(2), 163-178. doi: 10.1177/096394709900800204

Frascara, J. (1988). Graphic design: Fine Art or Social Science? Design Issues, 5(1), 18 - 29. Retrieved from: http://www.jstor.org/stable/1511556

Frascara, J., Kalsi, A., Kneebone, P. (1987). Graphic design for development. Paper presented at 1987 UNESCO Conference, Division of Development and Artist Creation, Nairobi, Kenya. Retrieved from http://www.icograda.org/feature/current/articles1127.htm 
Grigsby, S. E. (2003). Socially responsible design: A visual health campaign promoting awareness of the type 2 diabetes epidemic threatening children and adolescents in the united states. (Unpublished master's thesis, The University of Tennessee at Chattanooga).

Guernica (painting). (2012, April 5). In Wikipedia, The Free Encyclopedia. Retrieved 17:13, April 9, 2012, from http://en.wikipedia.org/w/index.php?title=Guernica_(painting)\&oldid=485704664

Hall, S. (1982). The rediscovery of 'ideology': return of the repressed in media studies. In M. Gurevitch, T. Bennett, J. Curran, \& J. Woollacott (Eds.), Culture, society and the media (pp. 56-90). London and New York: Methuen.

Harrison, C. (2003). Visual social semiotics: Understanding how still images make meaning. Technical Communication, 50(1), 46-60. Society for Technical Communication. Retrieved from http://www.ingentaconnect.com/content/stc/tc/2003/00000050/00000001/art00007

Hairman, R., \& Lucaites, J. L. (2007). No caption needed: iconic photographs, public culture, and liberal democracy. Chicago, USA: The University of Chicago Press.

Howard, G. (2010). Dictionary of rhetorical terms. United States of America: Xlibris Corporation.

Iedema, R. (200 I). Analysing film and television: a social semiotic account of Hospital: An Unhealthy Business. In T. van Leeuwen \& C. Jewitt (Eds.), Handbook of Visual Analysis (pp. 183-206). London: Sage.

Jewitt, c., \& Oyama, R. (2001). Visual meaning: a social semiotic approach. In T. van Leeuwen \& C. Jewitt (Eds.), Handbook of Visual Analysis (pp.134-156). London: Sage.

Ki-Moon, B. (2009, July). Building peace is about much more than ending war. Remarks during security council debate on post-conflict situations Un security council meeting. Retrieved from http://www.un.org/News/Press/docs/2009/sgsm12376.doc.htm

Kress, G. R., \& Leeuwen, T. V. (2006). Reading images, the grammar of visual design. (2nd Edition ed.). London, England: Psychology Press.

Milani, A. (2008). Greener shirts - Armando Milani. Retrieved from http://greenershirts.com/Armando_Milani.html

Milani, A. (2011). Alliance graphic international - members: Milani. Retrieved from http://www.a-g-i.org/?lid=2065\&tmpl=images\&imgid=17351

O’Toole, L.M. (1990) 'A Systemic-Functional Semiotics of Art', Semiotica 82 (3/4): 185-209. 
Rigby, A. (1998). A peace symbols origins. Peace Review, 10(3), 475-479. Retreived from http://ezproxy.lib.ryerson.ca/login?url=http://search.proquest.com/docview/217517628?a ccountid $=13631$

Riley, H. (2004). Perceptual modes, semiotic codes, social mores: a contribution towards a social semiotics of drawing. Visual Communication, 3(3), 294-315. doi:

$10.1177 / 1470357204045784$

Rose, G. (2012). Visual methodologies: an introduction to researching with visual materials. (3rd Edition ed.). London: Sage.

Rosenthal, P. (1994). How on earth does an olive branch mean peace? Peace and Change: A Journal of Peace Research, 19: 165-179. doi: 10.1111/j.14680130.1994.tb00605.xSAMARA

Rowan University - Armando Milani gallery talk. (8, December 2011). Retrieved from http://www.phillyfunguide.com/event/detail/440842144/Armando_Milani_Gallery_Talk

Samara, T. (2007). Design elements : a graphic style manual. Beverly, MA: Rockport Publishers.

Sasaki, S. (2008, October). The role of graphic design in international development. Paper presented at Seoul's 2008 Design Olympiad, Seoul, South Korea. Retrieved from http://www.icograda.org/feature/current/articles1814.htm

Sturken, M., \& Cartwright, L. (2000). Practices of looking: An introduction to visual culture. OUP Oxford.

Shank M and Schirch L (2008). Strategic arts-based peacebuilding. Peace and Change: A Journal of Peace Research, 33(2).

The united nations at a glance. (n.d.). Retreived from http://www.un.org/en/aboutun/index.shtml Un news centre - palestinian pupils at un schools form group image as dove of peace. (2011, November 25). Retrieved from http://www.un.org/apps/news/story.asp/\%20http://www.un.org/apps/sg/html/www.unama afg.org/news/_pc/_english/2008/\%27http://www.unep.org/Documents.Multilingual/story. asp?NewsID $=40520 \& \mathrm{Cr}=$ palestin $\& \mathrm{Cr} 1=$

Van Leeuwen, T. 92005) Introducing Social Semiotics. London: Routledge.

Walsh, D. (2003, February 8). Un conceals picasso's “guernica” for powell's presentation. World Socialist Website, Retrieved from http://www.wsws.org/articles/2003/feb2003/guer-f08.shtml

Zelizer, C. (2003). The role of artistic processes in peacebuilding in Bosnia-Herzegovina. Peace \& Conflict Studies, 10, 2, 62-75. 